\title{
Measuring evaporation from soil surfaces for environmental and geotechnical purposes
}

\author{
G E Blight \\ Department of Civil Engineering, University of the Witwatersrand, Johannesburg, Private Bag 3, WITS 2050, South Africa
}

\begin{abstract}
There are many reasons for the need to assess rates and quantities of evaporation or evapotranspiration from natural soil surfaces, the surfaces of deposits of mine or industrial waste, or soil-covered waste surfaces. These include assessing water balances for nearsurface soil strata, landfills, tailings dams and waste dumps and suitable deposition or application intervals for hydraulic fill tailings dams, or for the disposal of liquid wastes on land. The surface energy balance is probably the most widely used method for assessing evaporation, although other methods are also available. The surface energy balance method is studied in this paper.

The surface energy balance is by no means a new method (it was proposed by Bowen in 1926), but appears to be almost unknown to civil engineers, and in particular to those engaged in geotechnical engineering or waste management. The aim of this paper is to draw attention to this useful technique and to show how it can be applied in many aspects of environmental geotechnics and waste management.

The paper describes the measurements made to assess the surface energy balance as well as its analysis, and presents the results of typical measurements. It also presents numerical values of the parameters and constants needed for the analysis. The experimental difficulties of the analysis are described and examined, and the method's accuracy is assessed by means of laboratory and field measurements. The paper is intended to be both informative and a practical guide to measuring evaporation in the field.
\end{abstract}

\section{List of terminology}

(In order of introduction into text, but excluding standard SI units)

$\begin{array}{ll}\mathrm{h} & =\text { hour } \\ \mathrm{d} & =\text { day } \\ \mathrm{r} & =\text { relative humidity } \\ \overline{\mathrm{r}} & =\text { average relative humidity } \\ \mathrm{T} & =\text { temperature } \\ \overline{\mathrm{T}} & =\text { average temperature } \\ \mathrm{R}_{\mathrm{A}} & =\text { solar radiation received at outer limit of atmosphere } \\ \mathrm{S}_{\mathrm{o}} & =\text { solar constant } \\ \alpha & =\text { planetary albedo } \\ \phi & =\text { latitude } \\ \delta & =\text { sun's declination } \\ \mathrm{R}_{\mathrm{i}} & =\text { incoming solar radiation at Earth's surface } \\ \mathrm{C} & =\text { atmospheric clarity } \\ \mathrm{R}_{\mathrm{n}} & =\text { net solar radiation received at earth's surface } \\ \mathrm{a} & =\text { albedo of ground surface } \\ \mathrm{G}_{\mathrm{H}} & =\text { soil or waste heat flux } \\ \mathrm{H}_{\mathrm{e}} & =\text { sensible heat flux } \\ \mathrm{L}_{\mathrm{e}} & =\text { latent heat flux for evaporation } \\ \mathrm{W}_{\mathrm{E}} & =\text { wind energy flux } \\ \mathrm{E}_{\mathrm{W}} & =\text { evaporation caused by wind } \\ \Delta & =\text { slope of saturated water vapour pressure vs. } \\ \gamma & =\text { temperature curve } \\ \gamma & =\text { constant in wet-dry bulb psychrometer equation } \\ \mathrm{u} & =\text { ratio of actual to potential hours of sunshine } \\ \mathrm{n} / \mathrm{D} & \end{array}$

$\Sigma \mathrm{G}, \Sigma \mathrm{H}, \Sigma \mathrm{L}_{\mathrm{e}}, \Sigma \mathrm{R}_{\mathrm{n}}$, etc. = heat or energy fluxes integrated over time

$\rho_{\mathrm{a}} \quad=$ density of air

011 476-8759 or 7177105 ; fax $011476-8759$ or 339 1762; e-mail: blight@civil.wits.ac.za

Received 15 February 2002; accepted in revised form 8 July 2002.
$\mathrm{C}_{\mathrm{a}} \quad=$ specific heat of air

$\mathrm{k}_{\mathrm{h}}^{\mathrm{a}} \quad=$ eddy diffusivity for heat in air

$\delta \mathrm{T} / \delta \mathrm{z}=$ temperature gradient with height above ground surface

$\mathrm{E}=$ evaporation or vapour flux

$\mathrm{k}_{\mathrm{v}} \quad=$ eddy diffusivity for vapour in air

$\delta \rho_{v} / \delta z=$ vapour density gradient with height above ground surface

$\lambda=$ latent heat of vaporization for water $\left(2470 \mathrm{~kJ} \cdot \mathrm{kg}^{-1}\right)$

$\mathrm{E}=$ ratio of molecular masses of water and dry air

$\delta \mathrm{e} / \delta \mathrm{z}=$ vapour pressure gradient with height above ground surface

$\mathrm{P} \quad=$ atmospheric pressure

$B=$ Bowen's ratio

$\mathrm{z}_{\mathrm{a}}=$ height of air affecting evaporation at ground surface

$\left(\Delta \overline{\mathrm{T}}_{\mathrm{a}}\right) \quad=$ average change of air temperature over height $\mathrm{z}_{\mathrm{a}}$

$[\mathrm{h}]_{\mathrm{z}_{\mathrm{S}}}^{\mathrm{z}_{\mathrm{R}}}=$ transfer coefficient for heat between surface

level $\left(\mathrm{z}_{\mathrm{S}}\right)$ and a reference level $\left(\mathrm{z}_{\mathrm{R}}\right)$

$\mathrm{t}=$ time interval

$\mathrm{T}\left(\mathrm{z}_{\mathrm{S}}\right), \mathrm{T}\left(\mathrm{z}_{\mathrm{R}}\right)=$ temperatures at $\mathrm{z}_{\mathrm{S}}$ and $\mathrm{z}_{\mathrm{R}}$ respectively

$\mathrm{T}_{1}, \mathrm{~T}_{2}=$ air temperatures at levels 1 and 2

$\mathrm{e}_{\text {sat }} \quad=$ saturated water vapour pressure at mean of $\mathrm{T}_{1}$ and $\mathrm{T}_{2}$

$\mathrm{r}=$ relative humidity. $\mathrm{r}_{1}, \mathrm{r}_{2}=$ relative humidities at levels 1 and 2

$\Delta \quad=$ slope of $\mathrm{e}_{\text {sat }}$ versus $\mathrm{T}$ curve

$\gamma \quad=.057 \mathrm{kPa} .{ }^{\circ} \mathrm{C}^{-1}=$ constant in equation (6a)

$\mathrm{u}_{1}, \mathrm{u}_{2} \quad=$ wind velocities

$\mathrm{z}_{1}, \mathrm{z}_{2} \quad=$ heights above ground surface

$\mathrm{z}_{\mathrm{G}} \quad=$ depth of soil or waste heated diurnally

$(\Delta \overline{\mathrm{T}}) \quad=$ average change of temperature over depth $\mathrm{z}_{\mathrm{G}}$

$\mathrm{C}_{\mathrm{G}} \quad=$ specific heat of soil or waste

$\rho_{\mathrm{G}} \quad=$ bulk density of soil or waste

$\mathrm{G}_{\mathrm{Gd}} \quad=$ specific heat of dry soil or waste

$\mathrm{C}_{\mathrm{w}} \quad=$ specific heat of water $\left(4.19 \mathrm{~kJ} \cdot \mathrm{kg}^{-1} \cdot{ }^{\circ} \mathrm{C}^{-1}\right)$

$\mathrm{w}=$ gravimetric water content of soil 


\section{Introduction}

As the following examples from the environmental geotechnics and waste management fields will show, it is often important to determine the rate of evaporation of water from the surface of a soil stratum, a waste deposit or a soil-covered waste deposit, especially in arid or semi-arid climates where water is a scarce commodity, or where seasonal cycles of precipitation and evaporation can cause damage to shallow foundations or make it difficult to maintain a wetland.

- The cost of make-up water in the milling circuit of a mine located in an arid area may be an important factor in the profitability of the operation (e.g. Steffens and Thomson 1997). Water lost by evaporation from both wet and dry tailings dam beaches may be a large component of the total water lost (e.g. Blight, 2001) and it is important to assess the magnitude of these losses accurately under various operating conditions and at different times of the year.

- It may be an option to dispose of polluted or mineralized water by spray-irrigating it over the surface of a dump of waste (e.g. power station fly ash or coal mine discards) in order to evaporate the water. Disposal by evaporation may be a viable process in arid and semi-arid climates where rates of evaporation are high. If so, it is necessary to know how much water can be evaporated at different times of the year so that the rate of irrigation can be controlled so as not to exceed the water absorption capacity of the waste deposit (Blight and Kreuiter 2000). In this way, the water can be disposed of without generating a pollution plume from the base of the waste deposit.

- Optimal operating conditions for tailings dam consolidation and stability often depend on reducing the water content of each successively deposited layer of tailings by sun-drying before depositing the next on top of it. It is then necessary to determine the time to allow between successive depositions (at various seasons) so that the excess water can drain and evaporate (e.g. Newson et al. 1997).

- Evaporation from the surface is usually a major component of the water balance of a municipal solid waste landfill. Here it is important to be able to assess rates of evaporation from intermediate or final cover layers (e.g. Schroeder et al. 1983).

- The successful management of extensive wetlands, either natural or artificial, depends on the water balance for the wetland. This is especially so if it is located in an arid or semiarid climate and the water needs to be supplemented to maintain wetland conditions. Rates of evaporation from the wetland through the seasons must be known in order to assess the water balance accurately. Similar needs apply to designing shallow foundations for structures on moisture sensitive (shrinkable or expansive) soils.

Data from evaporation pans (e.g. the standard American "A" pan or the Symons " $\mathrm{S}$ " pan) are often used as the basis for assessing evaporation or evapotranspiration from soil or waste surfaces. Because rates of evaporation or evapotranspiration from bare or vegetated soil or waste surfaces are not the same as pan evaporation rates, empirical correction factors (e.g. Penman 1948) are often used to estimate evaporation from soil or waste surfaces (as well as large expanses of water). Empirical factors are usually only accurate for the conditions under which they were derived, and do not necessarily account for the effects of progressive depletion of water in the soil as it dries out. It is obviously desirable to be able to check (or even establish) such factors by direct measurement.

Two conditions must be satisfied for water to evaporate from a soil surface. Firstly, there must be energy available to provide the latent heat necessary for evaporation, and secondly, the evaporated water molecules must be removed from the immediate vicinity of the surface so that further water molecules can freely leave the surface. The first condition is supplied by solar radiation with a possible energy input by wind, and the second by convectional mixing of the air above the surface, possibly assisted by the sweeping action of wind.

The most direct method of estimating evaporation or evapotranspiration is by considering the surface energy balance. The net incoming solar radiation at any location is converted into heat energy, heating the air above the soil surface and the soil itself, and into latent heat of evaporation or evapotranspiration from the soil surface. If the net incoming radiation and the energy consumed in heating the air and the soil can be measured, then the latent heat of evaporation from the soil can be estimated and hence the rate of evaporation of water deduced.

After presenting the results of some simple experiments designed to illustrate some of the phenomena of evaporation from soil, the paper will describe the surface energy balance, the instruments and procedures used and give illustrative results of measurements. The methods of analysis as well as physical constants and numerical values used in the calculations are given in a detailed appendix. The technology is not new and has been used for many years in hydrology, soil physics and agricultural engineering (e.g. Penman 1963, Hillel 1980, Shuttleworth 1991) but appears to be unfamiliar to most civil engineers working in the environmental geotechnics and waste management fields. This paper is intended to introduce the technique to engineers for their practical use, and to demonstrate its capabilities and deficiencies and its potential accuracy in assessing rates of evaporation. (It should be noted that the measurements described in the paper were made in a temperate climate, either near inland Johannesburg, South Africa (latitude $26^{\circ} \mathrm{S}$, altitude $1800 \mathrm{~m}$ ) or near coastal Cape Town (latitude $34^{\circ} \mathrm{S}$ ). )

\section{Simple experiments to illustrate the phenomena of evaporation from soil}

The following simple experiments will qualitatively illustrate some aspects of the phenomena of soil evaporation:

\section{Evaporation in windless conditions}

Figure 1 shows evaporation rates measured in a greenhouse under windless conditions. Three plastic plant pots, each of $250 \mathrm{~mm}$ diameter were used. Two (with drainage holes in the base) were filled with soil (a clayey loam). One of the pots was planted with grass seed (Eragrostis curvula). Once the grass was mature and growing vigorously, both soil-filled pots were well watered and allowed to drain to field capacity. The drainage holes in the third container were sealed with silicone rubber and it was filled with water. The three containers were weighed daily and the mass loss (in mm of water) has been plotted against elapsed time in Figure 1. The relative humidity of the air in the vicinity of the pots varied from $75 \%$ at dawn to $50 \%$ at noon, while the air temperature varied from $19^{\circ} \mathrm{C}$ at dawn to $29^{\circ} \mathrm{C}$ at noon.

Figure 1 shows that evaporation from the water surface took place at a constant rate $\left(3.2 \mathrm{~mm} \cdot \mathrm{d}^{-1}\right)$. Evaporation from the bare soil surface initially took place at a greater rate $4 \mathrm{~mm} \cdot \mathrm{d}^{-1}$ ) until the nearsurface water became depleted after five days. The evaporation rate then dropped to $3.2 \mathrm{~mm} \cdot \mathrm{d}^{-1}$ and then $1.5 \mathrm{~mm} \cdot \mathrm{d}^{-1}$. Evaporation from the grassed surface initially took place at $4.6 \mathrm{~mm} \cdot \mathrm{d}^{-1}(14 \%$ greater than the bare soil) and then fell to $3.2 \mathrm{~mm} \cdot \mathrm{d}^{-1}$ after five days 
(when the grass began to wilt) and then $1.5 \mathrm{~mm} \cdot \mathrm{d}^{-1}$ after seven days (when the grass began to die).

This experiment illustrates several principles that will be expanded on later:

- More evaporation may occur from a soil surface than from a water surface.

- Evaporation from a soil surface declines as the water available in the soil is depleted. Hence actual evaporation rates from soil may be considerably less than potential rates.

- Transpiration by vegetation adds to evaporation, but the sum of the two, evapotranspiration, is not greatly in excess of evaporation. Transpiration also declines as available water is depleted.

\section{The effect of wind on evaporation}

Figure 2 shows the results of a similar experiment designed to illustrate the effects of wind on evaporation rates. The experiments were similar to those described in Fig. 1, except that only two containers of soil (with bare soil surfaces) were used. One was kept in a calm (windless) atmosphere, the other was exposed to a stream of air from a greenhouse humidifier. Temperatures were much the same as for the first experiment, but relative humidities varied from $95 \%$ at dawn to $75 \%$ at noon (The relative humidity adjacent to both containers was similar).

Figure 2a shows the effect on evaporation rate of a $7 \mathrm{~km} \cdot \mathrm{h}^{-1}$ $\left(1.95 \mathrm{~m} \cdot \mathrm{s}^{-1}\right)$ wind. Whereas the soil surface in calm air evaporated $1.6 \mathrm{~mm} \cdot \mathrm{d}^{-1}$ of water, that exposed to moving air evaporated 3.7 $\mathrm{mm} \cdot \mathrm{d}^{-1}$. After two days the positions of the containers were interchanged and the evaporation from the container now exposed to wind increased to $3.3 \mathrm{~mm} \cdot \mathrm{d}^{-1}$ while the other, now in the windless area, declined to $0.9 \mathrm{~mm} \cdot \mathrm{d}^{-1}$. After $4.5 \mathrm{~d}$, evaporation rates from both containers declined further because of depletion of water.

Figure $2 \mathrm{~b}$ summarises the results of four similar experiments (using the same two containers of soil and starting from field capacity each time) in which wind velocities of 2, 4, 7 and $10 \mathrm{~km} \cdot \mathrm{h}^{-1}$ were maintained. The figures for $r$ and $T$ are, respectively, the mean relative humidity and mean air temperature during each experiment, and $\mathrm{a}$ and $\mathrm{b}$ for the relative evaporation $(\mathrm{a}+\mathrm{b}) / \mathrm{a}$, are defined in Fig. 2a. No clear trend for relative evaporation rate with increasing wind speed was found. After an initial increase from 1 to 2.4, the relative evaporation rate could be regarded as constant as the wind speed was increased.

This demonstrates that for the conditions of the experiment, even a low velocity air movement has the effect of increasing the evaporation rate considerably. If the air had not been humidified, the increase may have been even larger. However, this effect did not appear to increase with increasing wind speed.

\section{Characteristics of solar radiation}

Figure 3 shows successive positions and attitudes of the earth as it orbits the sun. The four positions shown are the two solstices and the two equinoxes. The diagram is labelled for the southern hemisphere. The important points to note are that because the axis of the earth is inclined at $231^{1} 2^{\circ}$ to the plane of its orbit, the noonday sun is directly overhead the equator at the two equinoxes and directly overhead either the Tropic of Capricorn or the Tropic of Cancer at the two solstices.

At noon at a particular spot on the Earth's surface, the solar power reaching the outer limit of the Earth's atmosphere is given by:

$$
\mathrm{R}_{\mathrm{A}}=\mathrm{S}_{\mathrm{o}}(1-\alpha)(\sin \phi \sin \delta+\cos \phi \cos \delta)
$$

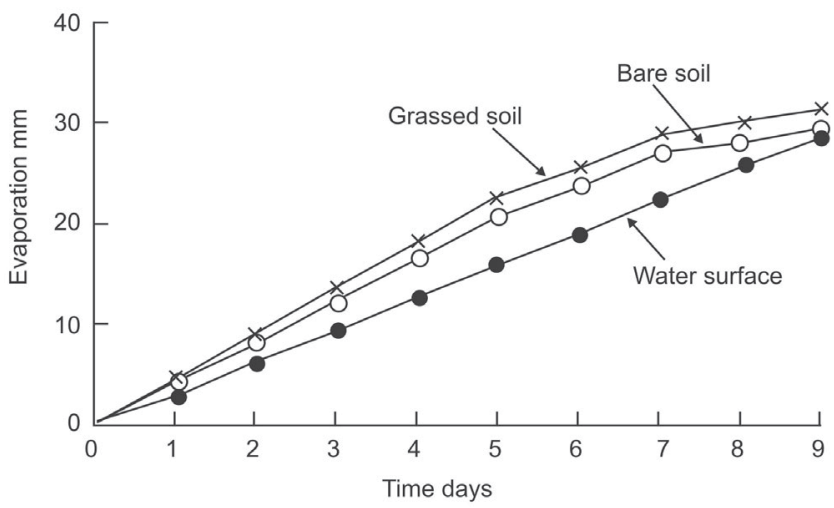

Figure 1

Comparison of evaporation from bare and grassed soil surfaces and a water surface
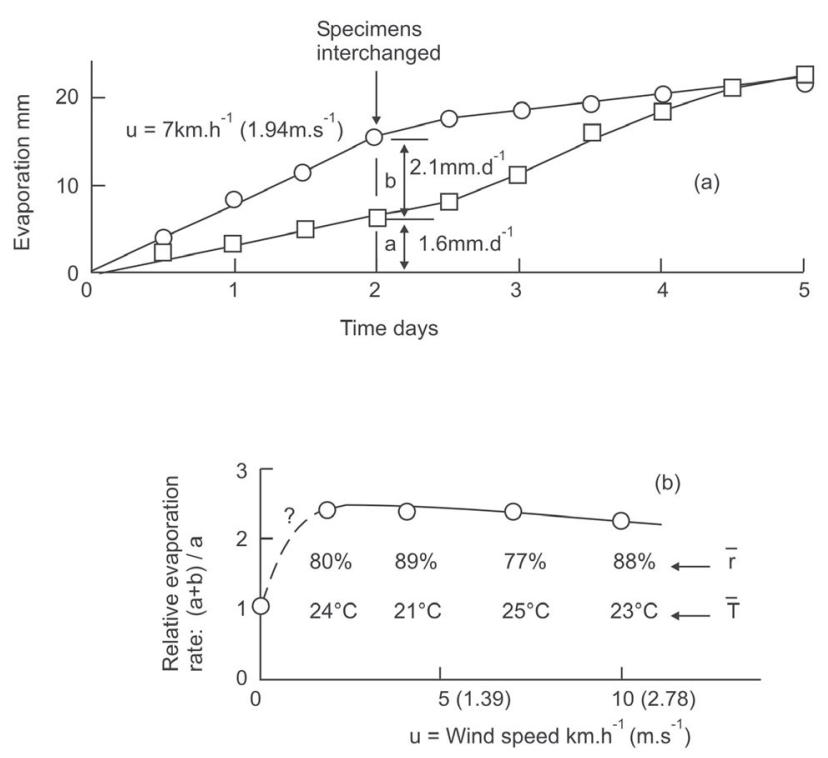

Figure 2

The effect of wind on evaporation from bare soil surfaces

where:

$\mathrm{R}_{\mathrm{A}}=$ net incoming radiation above the atmosphere (incoming minus reflected energy)

$\mathrm{S}_{\mathrm{o}}=$ solar constant $\left(=1380 \mathrm{~W} \cdot \mathrm{m}^{-2}\right)$

$\alpha^{\circ}=$ planetary albedo or the reflectance of the Earth. According to various authorities (e.g. Robinson, 1966, Tyson and Preston-Whyte, 2000), $\alpha$ varies from 0.3 to 0.5 with 0.4 being a reasonable average

$\phi=$ latitude of the place under consideration

$\delta=$ declination of the sun which varies from $0^{\circ}$ at the equinoxes to $23^{1} 2^{\circ}$ at the solstices.

Assuming $\alpha=0.4, \mathrm{~S}(1-\alpha)=828 \mathrm{~W} \cdot \mathrm{m}^{-2}$ which is the net incoming solar power at noon, on the Equator, at the equinoxes, or at the appropriate tropic (either Cancer or Capricorn) at the solstices. Figure 4 shows the variation of $\mathrm{R}_{\mathrm{A}}$ with latitude at the equinoxes, the northern summer solstice and the southern summer solstice.

The solar power can be converted into daily solar energy in 


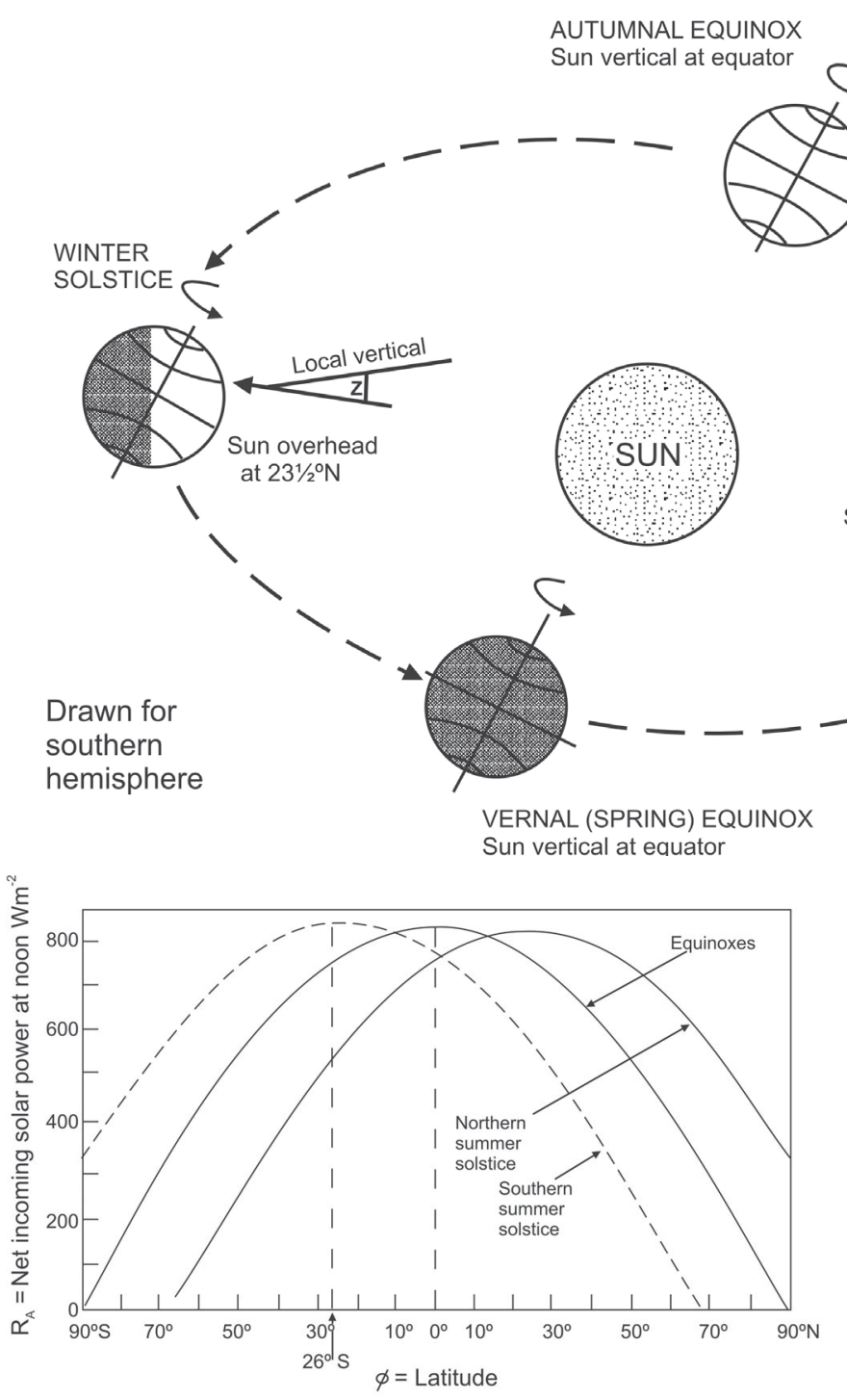

Figure 4

Variation of incoming noonday solar power with latitude and season

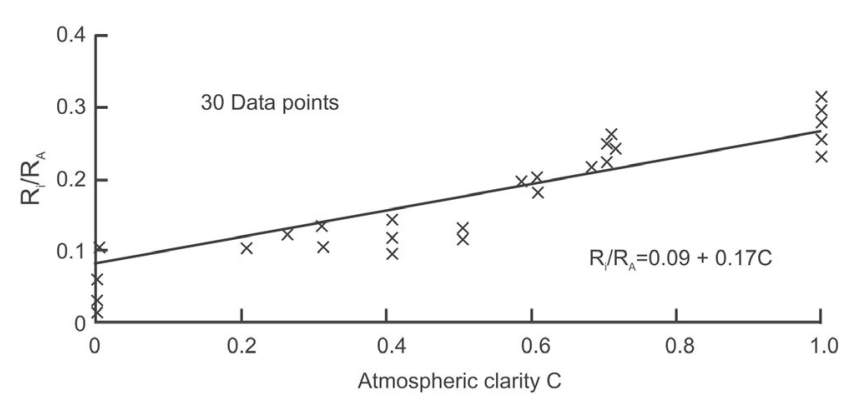

Figure 5

Effect of atmospheric clarity $C$ on solar energy received at Earth's surface $R_{i}$

$\mathrm{MJm}^{-2}$ by integrating the power over the length of the day from dawn to dusk. This can be done approximately by assuming that the power at a particular point varies through the day from sunrise to sunset in a parabolic fashion. For example the daily net solar energy at the outer limit of the atmosphere at the Equator at the equinox would be:

$$
2 / 3\left(828 \mathrm{Wm}^{-2} \times 12 \mathrm{~h} \times 3600 \mathrm{sh}^{-1}\right)=23.85 \mathrm{MJm}^{-2}
$$

However, what is required for practical use is not the power or energy at the outer limit of the atmosphere, but the quantity available at the surface of the earth. The intensity of solar radiation will be reduced considerably as a result of absorbtion by the atmosphere, reflection from high clouds and dust particles and reflection from the surface of the Earth. According to Flohn (1969) these losses amount to about $50 \%$ for nominally cloudless days, leaving the balance available for heating the near surface air and soil and for evaporating water from the soil. On cloudy days the radiation reaching the earth's surface is further reduced by interception and reflection from low altitude clouds.

Figure 5 shows the results of 30 measurements of the relationship between $R_{i} / R_{A}$ (where $R_{i}$ is the incoming solar radiation at the Earth's surface) and the atmospheric clarity C. C is the extent to which the sun's rays reach the Earth's surface unimpeded by cloud, i.e. $\mathrm{C}=1$ corresponds to a cloudless sky ( $100 \%$ clarity) and $\mathrm{C}=0$ to one that is completely overcast by cloud. Each data point represents the results of a complete day's observations in which $R_{i}$ was measured and $\mathrm{C}$ was assessed visually at hourly intervals throughout the day. The diagram shows that on average only $26 \%$ of $R_{A}$ is received at the earth's surface at the place of measurement (Johannesburg, South Africa, latitude $26^{\circ} \mathrm{S}$, altitude $1700 \mathrm{~m}$ AMSL) on a clear day. However, the ratio $R_{i} / R_{A}$ for $C=1$ will probably differ with latitude, altitude and climate.

\section{The surface energy balance}

$\mathrm{R}_{\mathrm{i}}$, the incoming solar radiation at the earth's surface is partly reflected by the surface albedo (a). Thus the net radiation at the surface is

$$
\mathrm{R}_{\mathrm{n}}=\mathrm{R}_{\mathrm{i}}(1-\mathrm{a})
$$

Conservation of energy requires that the energy consumed by evaporation must equal that supplied, while conservation of mass 
requires that the rate at which water vapour evaporates from the surface be equal to the rate at which it is dispersed into the atmosphere.

The surface energy balance, i.e. the way $\mathrm{R}_{\mathrm{n}}$ is converted at the ground surface is given by:

$$
\mathrm{R}_{\mathrm{n}}=\mathrm{G}+\mathrm{H}+\mathrm{L}_{\mathrm{e}}
$$

where:

$\mathrm{G}$ is the soil heat flux, the energy consumed in heating the near-surface soil

$\mathrm{H}$ is the sensible heat flux, the energy consumed in heating the air above the surface ("sensible" because this is the heat sensed or felt by the observer)

$\mathrm{L}_{\mathrm{e}}$ is the latent heat flux for evaporation, the heat consumed in evaporating water from the surface.

$R_{n}$ can be measured or estimated directly, $G$ can be estimated from changes in temperature of the near-surface soil and the specific heat capacity of the soil and $\mathrm{H}$ can be calculated in a similar way, or from temperature and relative humidity gradients in the near-surface air.

Equation (3) refers only to solar energy. If energy from an additional source is present (e.g. wind energy) a term describing this energy should be included. A modified form of Equation (3) including wind energy would be:

$$
\mathrm{R}_{\mathrm{n}}+\mathrm{W}_{\mathrm{E}}=\mathrm{G}+\mathrm{H}+\mathrm{L}_{\mathrm{e}}
$$

where:

$$
\mathrm{W}_{\mathrm{E}} \text { is the effective energy flux arising from the wind. }
$$

In the case of landfills or dumps of coal discards, heat supplied from the decomposing waste or spontaneously combusting carbonaceous material may also influence evaporation and should be added as a term in the surface energy balance (e.g. Bendz and Bengtsson 1996).

Data for calculating the surface energy balance can be collected automatically by monitoring and recording the outputs of a radiometer, heat flux plates, thermistors or thermocouples buried below the soil surface and psychrometers, used to measure air temperature and relative humidity gradients in the air above the surface.

Hand-held portable instruments can also be used to measure the components of the energy balance with less detail. Here the instrument cost is very much less and the system more flexible in its use, but labour costs are obviously higher and the data sets are discreet rather than continuous.

The energy fluxes of Eqs. (3) and (3a) are measured in Watts (Joules per second). When integrated over a period of time, e.g. 24 $\mathrm{h}$, the terms in the equations are expressed in Joules.

The basis for analysing Eq. (3) and evaluating its terms $\mathrm{H}, \mathrm{G}$ and $\mathrm{L}_{\mathrm{e}}$ is given in detail in Appendix A1.

\section{The Penman equations and the effect of wind}

The equations of conservation of energy and mass, as they apply to evaporation from a soil surface have the temperature of the surface as a common term. Penman $(1948,1963)$ solved the equations simultaneously to eliminate the surface temperature, and produced the equation for latent heat of evaporation:

$$
\mathrm{L}_{\mathrm{e}}=\frac{\Delta \mathrm{R}_{\mathrm{n}}+\gamma \mathrm{W}_{\mathrm{E}}}{\Delta+\gamma}
$$

where:

$\Delta$ is the slope of the saturation vapour pressure versus temperature curve (see Table A1 in the Appendix)

$\gamma$ is the constant in the wet-and-dry-bulb psychrometer equation $\left(0.057 \mathrm{kPa} \cdot{ }^{\circ} \mathrm{C}^{-1}\right)$ (see Appendix, equation (A3(a))

Equation (4) refers to evaporation from a soil surface where water is freely available to evaporate, i.e. the relative humidity at the surface is 100\%. Extending Penman's equation, Monteith (1980) has shown that if the surface relative humidity is less than $100 \%$ and water is thus not freely available to evaporate, Eq. (4) can be modified to read:

$$
\mathrm{L}_{\mathrm{e}}=\frac{\Delta \mathrm{rR}_{\mathrm{n}}+\gamma \mathrm{W}_{\mathrm{E}}}{\Delta \mathrm{r}+\gamma}
$$

where:

$r$ is the mean relative humidity at the surface.

The original Penman Eq. (4) ignored the soil heat flux G. If this is included, Eq. (4a) becomes:

$$
\mathrm{L}_{\mathrm{e}}=\frac{\Delta \mathrm{r}\left(\mathrm{R}_{\mathrm{n}}-\mathrm{G}\right)+\gamma \mathrm{W}_{\mathrm{E}}}{\Delta \mathrm{r}+\gamma}
$$

When using the surface energy balance analysis, it has been usual to treat the effects of wind separately. For example, Penman's empirical expression for $\mathrm{E}_{\mathrm{w}}$, the evaporation caused by wind is:

$$
E_{\mathrm{w}}=2.6(0.5+0.15 \mathrm{u}) \mathrm{e}_{\text {sat }}(1-\mathrm{r}) \text { in } \mathrm{mm} \cdot \mathrm{d}^{-1}
$$

where

$\mathrm{u} \quad$ is the mean wind speed in $\mathrm{km} \cdot \mathrm{h}^{-1}$ at a height of $2 \mathrm{~m}$ and $\mathrm{e}_{\text {sat }}$ is the saturated water vapour pressure at the prevailing temperature in $\mathrm{kPa}$.

Penman originally advanced Eq. (5) as applicable to evaporation from water surfaces. For cropped land, Penman suggested replacing the constant 0.5 by 1.0. Because the equation is empirical, various values for the constants have been used, depending on local conditions. See e.g. Doorenbos and Pruitt (1977).

Equation (5) predicts a linear increase of wind-associated evaporation with wind velocity u, which the data of Fig. 2 do not support. Also, Monteith (1980) has stated categorically that the evaporation rate is not strongly dependent on either temperature or wind speed. In fact, transpiration from vegetation may even decrease with increasing wind speed due to closing of leaf stomata in order to conserve water. Apart from uncertainty as to the validity of Eq. (5), because most waste deposits stand higher than the surrounding terrain, they form obstructions that result in locally increased wind speed and air turbulence in windward areas and decreased wind speed and turbulence in leeward areas (see Blight and $\mathrm{Da}$ Costa 2001). Thus, estimating overall evapotranspiration from a waste deposit by the wind effect becomes a very uncertain procedure.

An alternative approach to estimating $\mathrm{E}_{\mathrm{w}}$ is to calculate the wind energy W directly, as described in the Appendix.

\section{The typical daily surface energy balance}

Figure 6 shows the results of a typical set of automated surface energy balance measurements (Campbell Scientific, 1987). The energy fluxes (in $\mathrm{W} \cdot \mathrm{m}^{-2}$, i.e. $\mathrm{J} \cdot \mathrm{s}^{-1} \cdot \mathrm{m}^{-2}$ ) are plotted as ordinates 


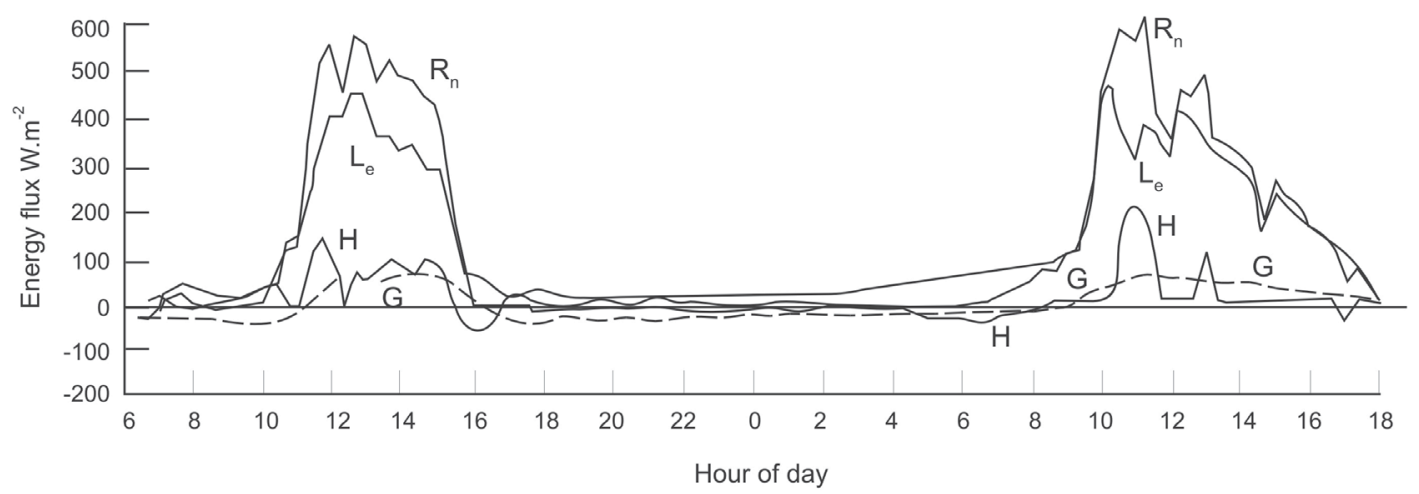

Figure 6

Typical

automated

measurements

of net incoming

radiation $R_{n}$,

sensible heat $H$,

soil heat $G$ and

latent heat for

evaporation $L_{e}$

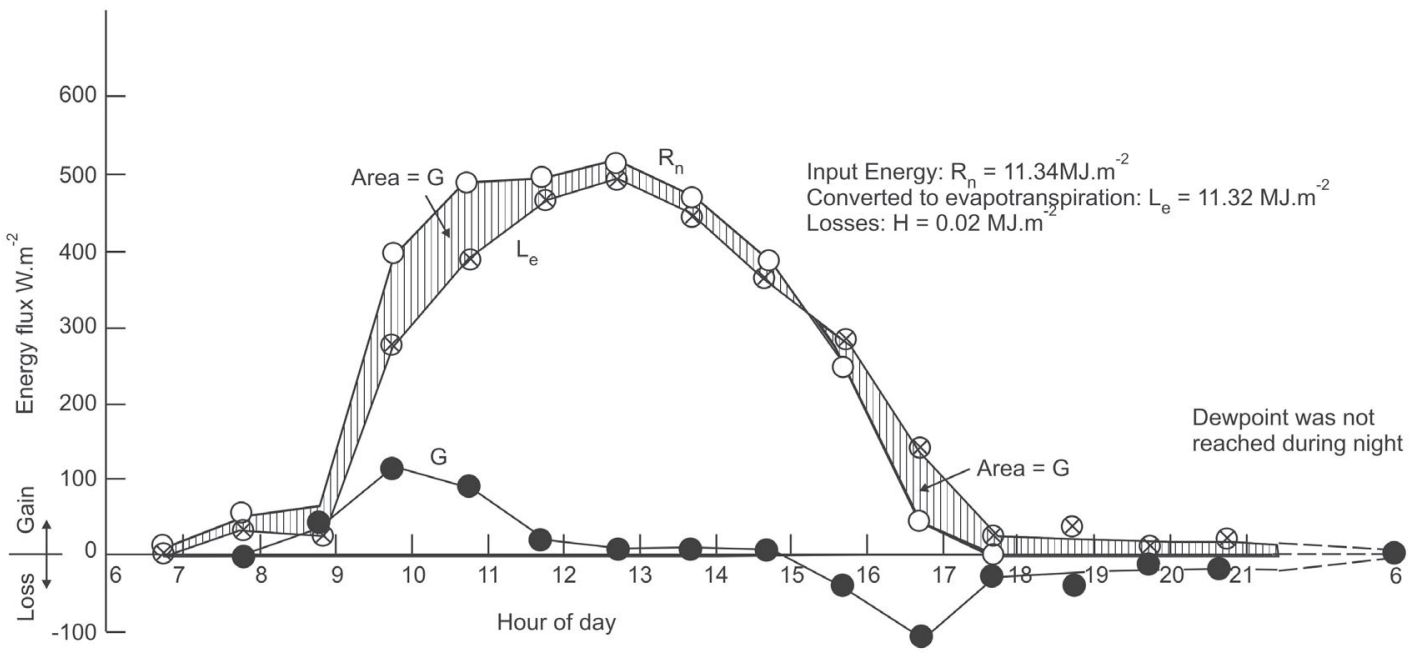

Figure 7

Set of surface energy balance measurements and corresponding calculated evapotranspiration, compared with measured A pan

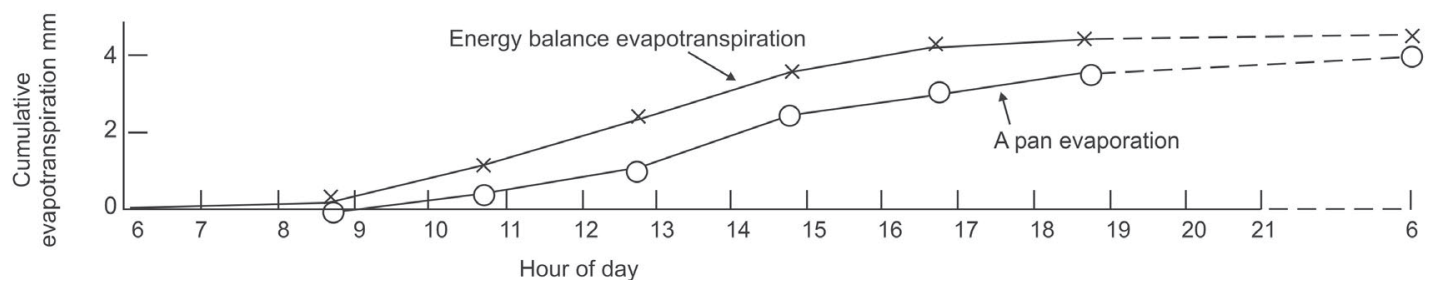
evaporation

against time as abscissae. The integral or area under each curve represents the energy gained (positive) or lost (negative) over a given time (in $\mathrm{J} \cdot \mathrm{m}^{-2}$ ). The measurements can also be shown cumulatively against time $\left(\Sigma \mathrm{R}_{\mathrm{n}}, \Sigma \mathrm{H}, \Sigma \mathrm{G}\right.$ and $\Sigma \mathrm{L}_{\mathrm{e}}$ versus time $)$, a method that has advantages, as the integration is done in the accumulation process.

There are a number of basic requirements that the curves in Fig. 6 should satisfy:

- $\mathrm{G}$ and $\mathrm{H}$ will usually be small in comparison with $\mathrm{L}_{\mathrm{e}}$.

- Because the earth is in a close radiation balance with surrounding space, neither $\mathrm{G}$ nor $\mathrm{H}$ should accumulate annually, although over a few weeks, if the weather changes or during a change of season, they may accumulate positively or negatively to a small degree. Essentially $\mathrm{G}$ or $\mathrm{H}$ gained in the day will be lost by outward radiation or reconverted at night.

- H will often become negative shortly after dawn as the dew (if dew has formed) evaporates, abstracting latent heat from the air.

- As G decreases in the late afternoon, it will be converted into latent heat of evaporation and $\mathrm{L}_{\mathrm{e}}$ may exceed $\mathrm{R}_{\mathrm{n}}$. This process will continue until the near-surface air temperature falls to the dew-point. After this the remaining $\mathrm{G}$ and $\mathrm{H}$ will be dissipated by long-wave radiation into the atmosphere and hence into space. Thus there will usually be a small amount of evaporation during the night even though incoming radiation is negligible.

Figure 7 shows the results of a typical set of measurements made at hourly intervals on a windless day over a vigorously growing grassed surface using a set of hand-held instruments (radiometer, thermocouple psychrometer and thermocouples buried at various depths in the soil. If there had been wind, an anemometer would have been used for regular wind speed measurements.) $\mathrm{H}$, calculated by the direct method (see Appendix) was too small to show on the plot (typically $1 \mathrm{~W} \cdot \mathrm{m}^{-2}$ as compared with up to $114 \mathrm{~W} \cdot \mathrm{m}^{-2}$ for $\mathrm{G}$ ).

Cumulative evapotranspiration during the day is shown (calculated from the energy balance) compared with cumulative evaporation measured by means of an adjacent class A evaporation pan. Because the grass was transpiring it is not unexpected that the calculated evapotranspiration exceeds the A pan evaporation (compare with Fig. 1).

The measurements were continued after sunset and show the slow dissipation of $\mathrm{G}$. The dew-point was not reached during the night but a small amount of evaporation (about $0.5 \mathrm{~mm}$ ) was recorded from the $\mathrm{A}$ pan and a similar quantity $(0.3 \mathrm{~mm})$ was 

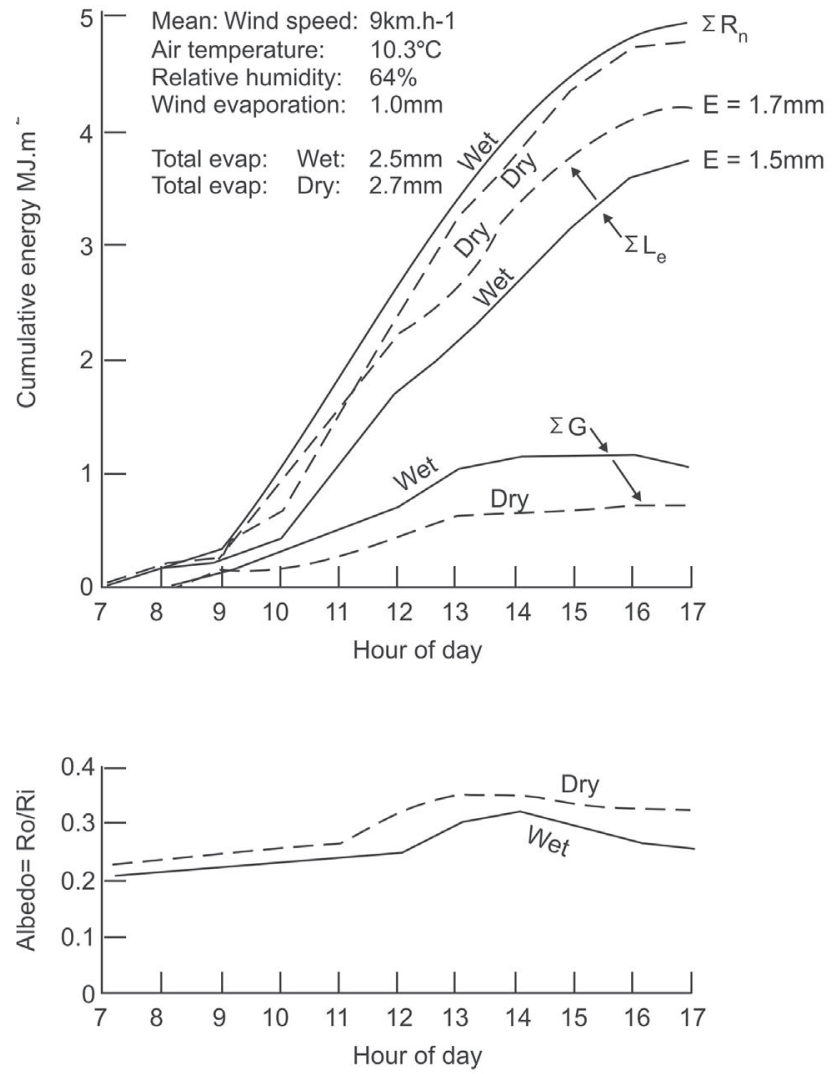

Figure 8

Set of comparative measurements for assessing evaporation from visibly wet and apparently dry hydraulic fill tailings beaches

calculated for the dissipation of G. (It is possible that some of the $\mathrm{G}$ energy remaining at sunset was lost by long wave radiation).

\section{More examples of evaporation measurements}

\section{The effect of a wet or dry surface}

Hydraulic fill tailings impoundments are often operated on a seven to ten day cycle of deposition with roughly one seventh to one tenth of the hydraulic fill deposition or beach area being deposited on each day. This area is visibly wet for a day or so, while the remaining area usually appears dry although it remains moist to a varying degree just below the surface. When calculating the water balance for the impoundment, the question often arises as to whether the evaporation rate for a wet beach surface differs from that for an apparently dry surface.

Possible reasons for differing evaporation rates are:

- differing albedos or energy reflectances for wet and dry surfaces;

- differing permeabilities of the immediate surface layers; and

- differing soil suctions of the surface layers.

Figure 8 compares two sets of simultaneous surface energy measurements, one made for a visibly wet surface, the other for an apparently dry surface. The measurements have been shown as cumulative energy in $\mathrm{MJ} \cdot \mathrm{m}^{-2}$ (i.e. the time-integrated form of Figs. 6 or 7). The material was a power station fly ash, the wet surface had been deposited on the previous day and the dry surface a week previously. The two sites were adjacent (200 m apart) and the effect of wind has been calculated separately by Eq. (5).
The lower diagram shows that the albedo $\left(\mathrm{R} / \mathrm{R}_{\mathrm{i}}\right.$ where $\mathrm{R}_{\mathrm{i}}$ is the incoming radiation and $R_{0}$ the outgoing reflected energy) for the dry area was slightly higher than that for the wet area throughout the day, because of its lighter colour. This resulted in $\Sigma R_{n}$ for the wet surface being slightly larger than for the dry surface. The wet near-surface ash also heated up more and its $\Sigma \mathrm{G}$ was larger. This resulted in $\Sigma \mathrm{L}_{\mathrm{e}}$ for the wet surface being less than for the dry surface. The dry surface evaporated $1.7 \mathrm{~mm}$ (by radiation absorption) as compared with $1.5 \mathrm{~mm}$ for the wet surface. The wind evaporation calculated by Eq. (5) was $1 \mathrm{~mm}$ for both surfaces and the calculated evaporations for the two surfaces ended up being 2.7 $\mathrm{mm}$ for the apparently dry surface compared with $2.5 \mathrm{~mm}$ for the wet surface.

Hence the comparison shows that evaporation from wet and dry beaches will be practically the same, provided the relative humidity above the dry surface is close to $100 \%$, and the beach has not dried out to the extent that the surface permeability has been significantly reduced, thus limiting evaporative outflow.

\section{The effects of transpiration by growing vegetation on evaporation losses}

The surfaces of rehabilitated waste dumps, landfills and tailings impoundments are often covered with a soil growing layer and planted with vegetation (usually grasses) or else vegetation is planted directly into the surface of the waste (with or without preparatory treatment) or establishes itself naturally from windborne seed, etc. The presence of the vegetation has a number of potential effects on evaporation or evapotranspiration from the surface:

- The vegetation changes the albedo of the surface.

- It directly shades the surface, intercepting net incoming radiation and reducing heating of the near-surface soil or waste.

- Part of the net radiation is expended on heating the leaves and stems of the vegetation.

- Grasses and other vegetation may die down either in the winter or in the dry season.

During the growing season vegetation may add to evaporation from the soil by transpiring water from the stomata in the leaves, but this source of water loss is not present when the vegetation is dormant.

The first two of these effects are illustrated by Fig. 9 which shows the results of two sets of measurements taken on the same day on the surface of a landfill, one set for a soil-covered area vegetated with thick, well-established grass, the other for an area covered by soil but with no vegetation.

The mid-section of Fig. 9 shows measured values of the albedo for the two surfaces. The albedo for the grassed surface was consistently lower than for the light-coloured bare soil surface.

The lower section shows soil surface temperatures, temperatures at the top of the grass canopy (about $200 \mathrm{~mm}$ above the surface), and air temperatures at $200 \mathrm{~mm}$ above the bare soil surface. Although the temperature at the top of the canopy increased considerably, the shading of the grass kept the temperature of the underlying soil surface consistently less (up to $10^{\circ} \mathrm{C}$ ). In contrast, the temperature of the bare soil surface was higher than that of the air (at $200 \mathrm{~mm}$ above the soil surface), and both temperatures were above the corresponding temperatures for the grassed surface for much of the day.

The effects of these differences are shown in the top section of Fig. 9. $\Sigma \mathrm{G}$ was less for the soil under the grass than for the bare soil and because of the lower albedo, $\Sigma \mathrm{R}_{\mathrm{n}}$ was higher for the grassed area. Similarly, $\Sigma \mathrm{L}_{\mathrm{e}}$ was higher for the grassed surface than for the 

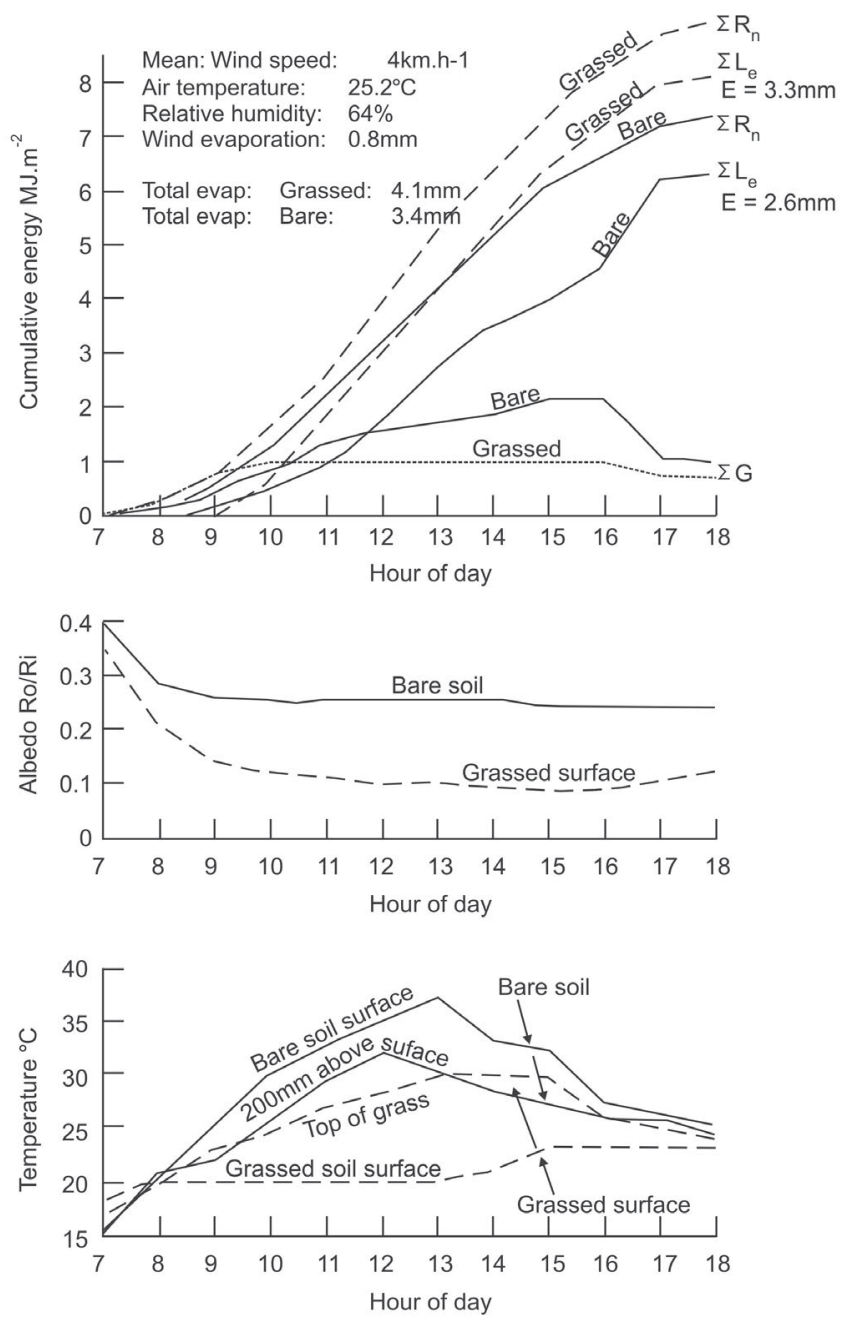

Figure 9

Set of comparative measurements to demonstrate the effects of vegetation on evaporation from a soil surface bare soil. Including the wind evaporation (Eq. (5)), total evaporation for the grassed surface was $4.1 \mathrm{~mm}$ for the day while it was $3.4 \mathrm{~mm}$ for the bare soil surface. It is difficult to assess the contribution to evapotranspiration of the grass cover alone as the water is drawn from the soil through the root system and then evaporates through stomata on the leaf surfaces.

To investigate the amount of solar radiation absorbed in heating plant or grass leaves and stems, two areas each $1 \mathrm{~m}^{2}$ in area, one covered by a thick, short $(0.3 \mathrm{~m})$ succulent grass (Cynodon dactylon) and the other by a longer $(0.8 \mathrm{~m})$ more woody grass (Hyparrhenia hirta) were cut down to ground level. The grass from each area was carefully collected and weighed, then dried and reweighed. The results and an analysis of them are given in Table 1.

Table 1 shows that the greater error in calculating $G$ for these two areas if heating of the surface vegetation were ignored would be $8.3 / 612=1.4 \%$ and the lesser would be $1.5 / 612=0.2 \%$.

Considering the results of the paired set of measurements given above, it appears that the most important effects of vegetation lie in the change of albedo of the surface and the direct interception of solar energy by the vegetation canopy.

When the vegetation has died down (e.g. during winter or as a result of drought) similar shading effects persist, but the dormant vegetation does not transpire. The albedo increases because of the lighter colour of the dry vegetation, and evaporation decreases.

\section{The increasing importance of $\mathrm{G}$ as the soil dries out}

Reference to the early hours after sunrise in Figs. 8 and 9 will show that initially, the entire $\Sigma \mathrm{R}_{\mathrm{n}}$ is converted into $\Sigma \mathrm{G}$ and $\Sigma \mathrm{L}_{\mathrm{e}}$ remains zero until 08:00 or 09:00. As the surface soil dries out, this effect is accentuated. Figure 10 shows a set of measurements in which an attempt was made to assess the effect of uncertainty in calculating $\mathrm{G}$ as the soil dried out during the day and its water content reduced. Allowing for this uncertainly, $\Sigma \mathrm{R}_{\mathrm{n}}$ could have been completely converted into $\Sigma$ G until either 09:30 or 13:00. The effect of this is to bring an uncertainty of $0.3 \mathrm{~mm}(25 \%)$ into the calculated evaporation $\mathrm{E}$. As the decline in $\Sigma \mathrm{G}$ was partly the result of longwave radiation losses, the actual value of $E$ could have been as small as $0.6 \mathrm{~mm}$, an uncertainty of $50 \%$ of the maximum value of $1.2 \mathrm{~mm}$.

It will also be noted that in this example, $\Sigma \mathrm{G}$ exceeded $\Sigma \mathrm{L}_{\mathrm{e}}$ throughout the day. Thus in some circumstances most of the incoming energy can be consumed in heating the soil, leaving little to provide latent heat of evaporation.

\section{Estimating annual evapotranspiration}

Water content:

$\mathrm{G}$ (grass)*

Assumed soil density:

Analysis of surface vegetation

Mass of soil per $\mathrm{m}^{2}$ subjected to daily solar heating

(down to $0.2 \mathrm{~m}$ ):

Specific heat of soil*:

$\mathrm{G}$ (soil) per ${ }^{\circ} \mathrm{C}$ temperature change:
$360 \mathrm{~kg}$

$1.7 \mathrm{~kJ} \cdot \mathrm{kg}^{-1} \cdot{ }^{\circ} \mathrm{C}^{-1}$

$612 \mathrm{~kJ} \cdot{ }^{\circ} \mathrm{C}^{-1}$
*Calculated from Eq. (A8) in Appendix.
So far only daily evapotranspiration has been considered. However, it is often far more important to estimate annual or seasonal evapotranspiration. Even if continuous recordings of the energy balance components are made over a season or a year, the measurements may not be representative of long term conditions. If only isolated daily measurements are made, even if these are regular monthly or weekly measurements, the problem is even more difficult. 
Two approaches have been tried by the author, and these will be illustrated for the site of a landfill at Coastal Park in Cape Town where long-term (15 year) measurements of rainfall and leachate flow have been made (Blight 1997). As the outer cover layer of the Coastal Park landfill is a pervious dune sand, there is no significant runoff, and hence:

Rainfall - leachate $=$ evaporation .

The first approach was to use values for $\mathrm{R}_{\mathrm{i}}$ calculated from Eq. (1) and Fig. 5. Penman (1963) has published an empirical equation applicable for conditions in southern England:

$$
\mathrm{R}_{\mathrm{i}} / \mathrm{R}_{\mathrm{A}}=0.25+0.54 \mathrm{n} / \mathrm{D}
$$

where $n / D$ is the ratio of the actual number of hours of sunshine to the potential number of hours of sunshine. The measurements shown in Fig. 5, are not as optimistic as Eq. (6). For fully clouded conditions they predict that $R_{i} / R_{A}=0.09$, whereas Penman's equation predicts that $R_{i} / R_{A}=0.25$.

Long-term (30 years) measurements of daily cloud cover are available for the Cape Town site and these were used to estimate monthly average values of clarity $C$. Thus $\Sigma \mathrm{R}_{\mathrm{i}}$ could be estimated month by month. $\Sigma \mathrm{R}_{\mathrm{i}}$ was then reduced to allow for the measured albedo of the site (0.1) to give $\Sigma \mathrm{R}_{\mathrm{n}}$ and $\Sigma \mathrm{R}_{\mathrm{n}}$ was then multiplied by a factor of 0.83 to give $\Sigma \mathrm{L}_{\mathrm{e}}$. This factor was obtained from the correlation between $\Sigma \mathrm{L}_{\mathrm{e}}$ and $\Sigma \mathrm{R}_{\mathrm{n}}$ measured by isolated one-day measurements at the site and is shown in Fig. 11. The resultant value for the annual latent heat of evaporation was:

$$
\Sigma \mathrm{L}_{\mathrm{e}}=1431 \mathrm{MJ} \cdot \mathrm{m}^{-2}
$$

Dividing by the latent heat of evaporation of $2.47 \mathrm{MJ} \cdot \mathrm{kg}^{-1}$ gives an annual evaporation of:

\section{$579 \mathrm{~kg} \cdot \mathrm{m}^{-2}$ or $579 \mathrm{~mm}$ of water}

Fifteen year average annual measurements for the site are:

$$
\begin{aligned}
& \text { Rainfall } R=620 \mathrm{~mm} \\
& \text { Leachate flow } \mathrm{L}=15 \mathrm{~mm} \\
& R-L=\text { evapotranspiration }=605 \mathrm{~mm}
\end{aligned}
$$

Hence:

Estimated/actual evapotranspiration $=579 / 605=96 \%$.

The second approach was to regard the A pan evaporation recorded for the site as a good indication of the value of $R_{i}$. Figure 12 shows a correlation between the long-term average $A$ pan evaporation and corresponding evaporation measured on site by the energy balance.

Figure 12 establishes that the cumulative evaporation by energy balance averages 0.45 of the cumulative A pan evaporation. The annual A pan evaporation is $1620 \mathrm{~mm}$, and hence the annual evaporation by energy balance should be $711 \mathrm{~mm}$. Thus by this method:

\section{Estimated/actual evapotranspiration $=711 / 605=118 \%$}

Thus both methods appear to yield reasonable estimates of annual evapotranspiration. Of the two, the second method is probably fundamentally the better, as extrapolation using a diagram like Fig. 12 seems more direct than the method using Fig. 11. Also, the effect of wind on evaporation would automatically be included in Fig. 12, but not in Fig. 11, and this may be one reason for the difference between the two estimates.

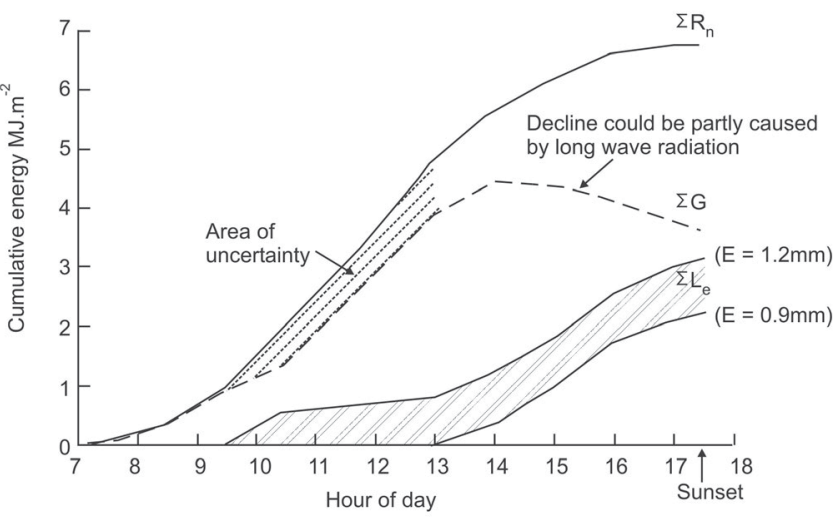

Figure 10

The effect of uncertainty in calculating $G$ on estimated soil evaporation

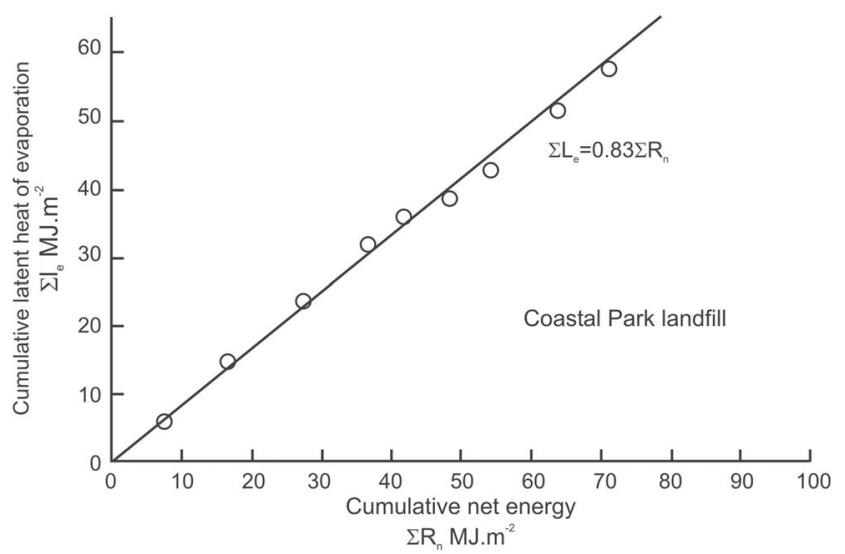

Figure 11

Correlation between cumulative net radiation $R_{n}$ and cumulative latent heat for evaporation $L_{e}$ for Coastal Park site

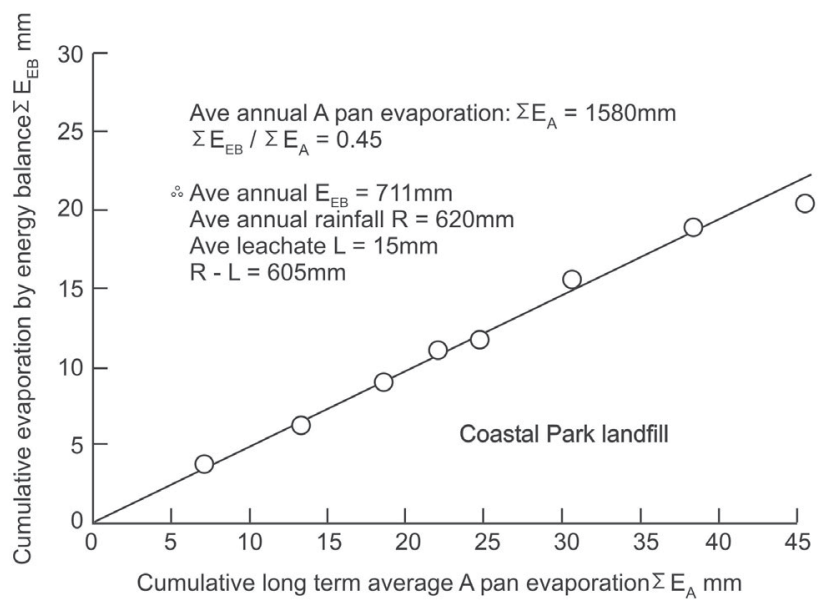

Figure 12

Assessment of annual evapotranspiration at Coastal Park site by comparing $E_{E B}$ with $E_{A}$ 

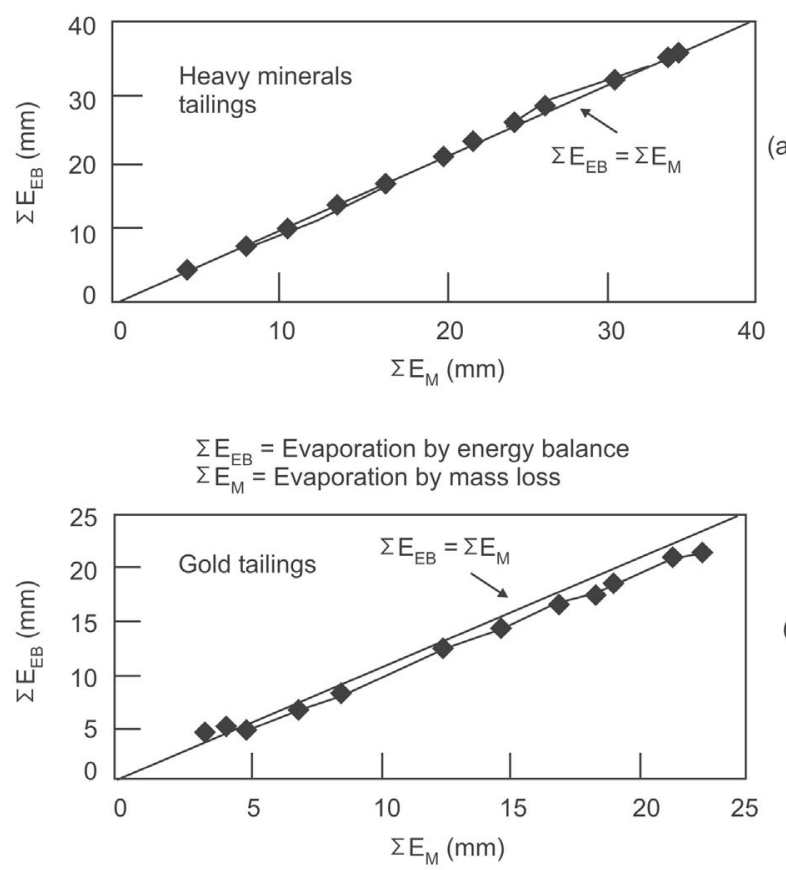

(b)

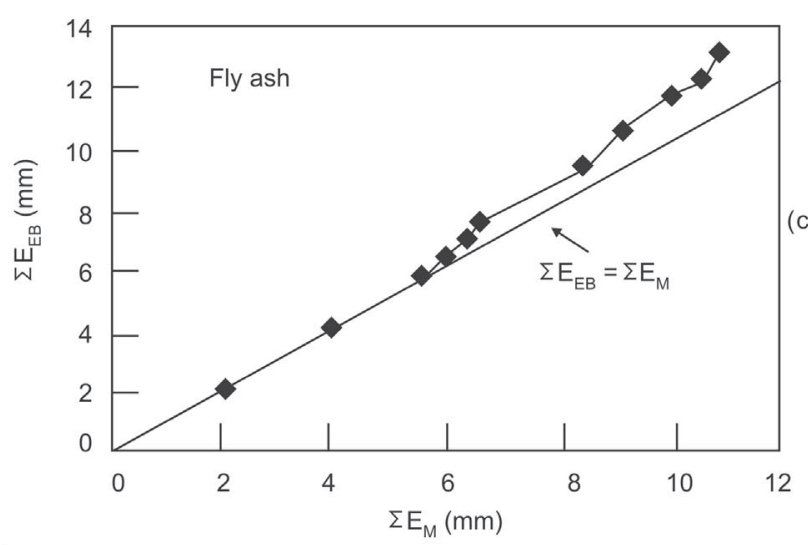

Figure 13

Assessment of accuracy of surface energy balance measurements applied to measuring evaporation from tailings surfaces in the laboratory

\section{Examples illustrating potential acuracy of the energy balance method}

Checking the accuracy of evaporation measured by means of the surface energy balance is difficult because of the difficulty of establishing an absolute basis for comparison. Three examples of accuracy checks will be given here, one for laboratory measurements and two for field measurements.

Blight and Lufu (2000) describe a series of tests in which evaporation from trays of wet mine tailings kept in a greenhouse (to eliminate the effects of wind and rain) was estimated by the surface energy balance and checked by direct weighing. The results of these measurements, for three different types of tailings, are shown in Fig. 13. Evaporation found by energy balance $\left(\Sigma \mathrm{E}_{\mathrm{EB}}\right)$ has been plotted against evaporation from mass loss $\left(\Sigma \mathrm{E}_{\mathrm{M}}\right)$ of the trays. The comparison was excellent for the heavy minerals tailings, but less so for the gold tailings (maximum error an underestimate of $2 \mathrm{~mm}$ in 23 or $9 \%$ ) and the fly ash (maximum error an overestimate of
$\Sigma E_{E B}=$ Evaporation by energy balance $\Sigma E_{\mathrm{ML}}=$ Evaporation by micro lysimeter

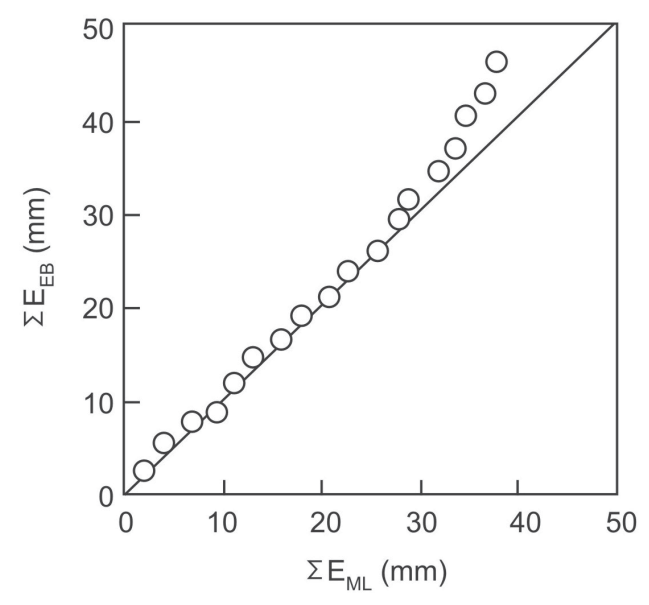

Figure 14

Comparison of cumulative surface energy balance $\left(E_{E B}\right)$ and microlysimeter $\left(E_{M 1}\right)$ measurements of evaporation from a grassed soil surface

$2 \mathrm{~mm}$ in 13 or $15 \%$ ). Errors were found to increase as the tailings became drier.

The second example relates to Fig. 8 where an independent check on evaporation was made using the microlysimeter technique (Boast and Robertson, 1982). A microlysimeter consists of an open-ended coring tube (in this case $150 \mathrm{~mm}$ in diameter by 150 $\mathrm{mm}$ long that is used to remove a core of soil. The core is left in the tube, and its base is sealed using wax or a plastic sheet. The core is then replaced in the hole from which is was taken. Daily measurements of evaporative loss are made by removing the microlysimeter and weighing it.

As shown in Fig. 8, the total evaporation for the day averaged $2.6 \mathrm{~mm}$. The results for four microlysimeters, two in the "wet" area and two in the "dry" ranged from 2.3 to $2.9 \mathrm{~mm}$, i.e. ratios varied from $90 \%$ to $113 \%$.

The third example relates to a second comparison of energy balance and microlysimeter measurements. Figure 14 compares evapotranspiration estimated by energy balance $\left(\Sigma \mathrm{E}_{\mathrm{EB}}\right)$ with microlysimeter measurements $\left(\mathrm{E}_{\mathrm{ML}}\right)$ for a soil surface covered by short mown grass. The measurements were taken over a period of $21 \mathrm{~d}$. At the start, the mean of the four microlysimeters agreed very well with the energy balance measurements, but later the energy balance showed greater evaporations than the microlysimeters. Because the soil cores in the microlysimeter tubes were sealed at the bottom, the validity of the measurements only extends over a few days (perhaps a week). The divergence of measurements at later times should, therefore, be disregarded. This was, in fact, a very satisfactory comparison of one method with the other.

In summary, it is reasonable to say that the surface energy balance method of measuring evaporation has an accuracy that depends on the circumstances and way in which it is used. Accuracies in the range of $\pm 10 \%$ appear to be attainable, but the accuracy may be much worse, especially when only a few sets of measurements are available and when dealing with dry soils.

\section{Concluding summary}

This paper has illustrated aspects of evaporation from soil surfaces by means of simple experiments and gives practical examples of measuring evaporation or evapotranspiration by means of the 
surface energy balance. The results of typical sets of measurements of the effect of surface wetness on evaporation from hydraulic fill tailings beaches, and the effects of vegetation on evaporation rates from soil surfaces were presented. It appears (on the basis of comparative measurements) that visibly wet and apparently dry surfaces evaporate water at essentially the same rate, although surfaces that are dry enough for the surface relative humidity to be below $100 \%$ will evaporate water at lower rates. The major effects of vegetation (also based on comparative measurements) are to alter the albedo of the ground surface and to intercept solar energy by shading the underlying soil. If the vegetation is actively transpiring, evaporation will be slightly larger from a vegetation covered surface than from a bare surface. For dry soils, heat absorption by the soil becomes a major term in the surface energy balance.

Two methods were proposed for estimating annual evapotranspiration, both of which appear to give reasonably representative estimates.

Analyses of the accuracy of the surface energy balance method in measuring evaporation from soil showed that depending on circumstances, the accuracy can be better than $\pm 10 \%$, although it may not be as good when only a few sets of measurements are available or when the moisture below the soil surface is not freely available for evaporation.

A better knowledge of the effects of wind on rates of evaporation is needed.

\section{References}

BENDZ D and BENGTSSON L (1996) Evaporation from an active, uncovered landfill. J. Hydrol. Elsevier, Amsterdam, Netherlands. 182 143-155.

BLIGHT GE (1997) Interactions between the atmosphere and the Earth. (37th Rankine Lecture). Geotechnique. London, United Kingdom. 47 (4) 715-767.

BLIGHT GE (2001) Evaporation from wet and "dry" beaches of tailings dams. Tailings andMine Waste '01. Balkema, Rotterdam, Netherlands. 33-39.

BLIGHT GE and KREUITER A (2000) Disposal of industrial waste liquids by evaporation and capillary storage in waste dumps. Tailings and Mine Waste '00. Balkema, Rotterdam, Netherlands. 141-148.

BLIGHT GE and LUFU L (2000) Principles of tailings de-watering by solar evaporation. Tailings and Mine Waste '00. Balkema, Rotterdam, Netherlands. 55-64.

BLIGHT GE and DA COSTAFA (2001) On the mechanics of wind erosion from tailings dams. Tailings and Mine Waste '01, Balkema, Rotterdam, Netherlands. 189-196.
BOAST CW and ROBERTSON TM (1982) A microlysimeter method for determining evaporation from bare soil: Description and laboratory evaluation. J. Soil Sci. Soc. of Am. 46 689-696.

BOWEN IS (1926) The ratio of heat losses by conduction and by evaporation from any water surface. Phys. Rev. United Kingdom. 27 779-787.

CAMPBELL SCIENTIFIC LTD (1987) Bowen Ratio System User Guide.

DOORENBOS J and PRUITT WO (1977) Crop Water Requirements. Food and Agricultural Organization, Irrigation and Drainage Paper 24. Rome, Italy.

FLOHN H (1969) Climate and Weather. Weidenfeld and Nicolson, London, United Kingdom.

HILLEL D (1980) Applications of Soil Physics. Academic Press, New York, USA.

LOWE PR (1976) An approximate polynomial for computation of saturation vapour pressure. J. Appl. Meteorol. London, United Kingdom. 16 100-103.

MONTEITH JL (1980) The development and extension of Penman's evaporation formula. In: Hillel D (ed.) Applications of Soil Physics. Academic Press, New York, United States of America.

NEWSON T, FUJIYASU Y and FAHEY M (1997) The evaporation behaviour of tailings. Tailings and Mine Waste '97. Balkema, Rotterdam, Netherlands. 137-146.

PENMAN HL (1948) Natural evaporation from open water, bare soil and grass. Proceedings. Royal Society, London, United Kingdom. Series A193 120-146.

PENMANHL (1963) Vegetation and Hydrology. Technical Communication No. 53. Commonwealth Bureau of Soils, Harpenden, United Kingdom.

PERRIER A and TUZET A (1991) Land surface processes: Description, theoretical approaches, and physical laws underlying their measurements. In: Schmugge TJ and Andre J-C (eds.) Land Surface Evaporation: Measurement and Parameterization. Springer-Verlag, New York, USA.

ROBINSON N (1966) Solar Radiation. Elsevier, Amsterdam, Netherlands. ROGERS GFC and MAYHEW YR (1995) Thermodynamic and Transport Properties of Fluids (5th edn.) Blackie, Oxford, United Kingdom.

SCHROEDER PR, MORGAN JM, WALSKITM and GIBSON AC (1983) The Hydrologic Evaluation of Landfill Performance (HELP) Model. US EPA Report No. EPA/DF-85/001a. Washington, USA.

SHUTTLEWORTH WJ (1991) Evaporation models in hydrology. In: Schmugge TJ and Andre J-C (eds.) Land Surface Evaporation Measurement and Parameterization. Springer-Verlag, New York, USA.

STEFFENS SD and THOMPSON GB (1997) Consumptive use of water associated with tailing pond deposition. Tailings and Mine Waste ' 97. Balkema, Rotterdam, Netherlands. 97-104.

TYSON PD and PRESTON-WHYTE RA (2000) The Weather and Climate of Southern Africa (2nd edn.). Oxford University Press, South Africa.

WILSON EM (1970) Engineering Hydrology. Gordon and Breach, New York, USA.

\section{Appendix}

\section{Analysing surface energy balance measurements}

\section{Analysis}

The analysis commonly used to divide the net radiation $\mathrm{R}_{\mathrm{n}}$ into its components G, $\mathrm{H}$ and $\mathrm{L}_{\mathrm{e}}$ is due to Bowen (1926). Bowen expressed $\mathrm{H}$ as:

$$
\mathrm{H}=\rho_{\mathrm{a}} \mathrm{C}_{\mathrm{a}} \mathrm{k}_{\mathrm{h}} \delta \mathrm{T} / \delta \mathrm{z}
$$

where

$$
\begin{aligned}
& \rho_{\mathrm{a}}=\text { density of air }\left(\mathrm{kg} \cdot \mathrm{m}^{-3}\right) \\
& \mathrm{C}_{\mathrm{a}}=\text { specific heat of air }\left(\mathrm{kJ} \cdot \mathrm{kg}^{-1} \cdot{ }^{\circ} \mathrm{C}^{-1}\right) \\
& \mathrm{k}_{\mathrm{h}} \quad=\text { eddy diffusivity for heat in air }\left(\mathrm{m}^{2}\right)
\end{aligned}
$$

$\delta \mathrm{T} / \delta \mathrm{z}=$ temperature gradient with height above ground level $\left({ }^{\circ} \mathrm{C} \cdot \mathrm{m}^{-1}\right)$.

$\mathrm{H}$ has units of $\mathrm{kJ} \cdot \mathrm{m}^{-2}$ (i.e. $\mathrm{kJ}$ per $\mathrm{m}^{2}$ of ground surface area).

The rate of evaporation or vapour flux, E, was expressed by Bowen as:

$$
\mathrm{E}=\mathrm{k}_{\mathrm{v}} \delta \rho_{\mathrm{v}} / \delta \mathrm{z}
$$

where:

$$
\begin{aligned}
\mathrm{k}_{\mathrm{v}}= & \text { eddy diffusivity for vapour in air }\left(\mathrm{m}^{2}\right) \\
\delta \rho_{\mathrm{v}} / \delta \mathrm{z}= & \text { vapour density gradient with height above ground } \\
& \text { level }\left(\mathrm{kg} \cdot \mathrm{m}^{-4}\right)
\end{aligned}
$$

$\mathrm{E}$ has units of $\mathrm{kg} \cdot \mathrm{m}^{-2}$ or $\ell \cdot \mathrm{m}^{-2}$ (equivalent to $\mathrm{mm}$ of water depth evaporated). 
$\mathrm{L}_{\mathrm{e}}$ can be written as:

$$
\mathrm{L}_{\mathrm{e}}=\lambda \rho \varepsilon \mathrm{k}_{\mathrm{v}}(\delta \mathrm{e} / \delta \mathrm{z}) / \mathrm{P}
$$

where:

$\lambda=$ latent heat of vaporization for water $\left(2470 \mathrm{~kJ} \cdot \mathrm{kg}^{-1}\right)$

$\varepsilon \quad=$ ratio of the molecular masses of water and dry air (dimensionless);

$\delta \mathrm{e} / \delta \mathrm{z}=$ vapour pressure gradient with height above ground level $\left(\mathrm{kPa} \cdot \mathrm{m}^{-1}\right)$

$\mathrm{P}=$ atmospheric pressure $(\mathrm{kPa})$.

$\mathrm{L}_{\mathrm{e}}$ has units of $\mathrm{kJ} \cdot \mathrm{m}^{-2}$.

Bowen then made the assumption that $\mathrm{k}_{\mathrm{h}}=\mathrm{k}_{\mathrm{v}}$, and dividing Eqs. (A1) and (A3):

$$
\mathrm{H} / \mathrm{L}_{\mathrm{e}}=\beta=\mathrm{PC}_{\mathrm{a}} / \lambda \varepsilon . \delta \mathrm{T} / \delta \mathrm{e}
$$

where:

$$
\mathrm{PC}_{\mathrm{a}} / \lambda \varepsilon=\gamma=0.057 \mathrm{kPa} \cdot{ }^{\circ} \mathrm{C}^{-1} .
$$

From Eqs. (3) and (A1):

$$
L_{e}=\frac{R_{n}-G}{1+\beta}
$$

$\beta$ is known as Bowen's ratio.

$\mathrm{L}_{\mathrm{e}}$ can then be expressed as evaporation or evapotranspiration by dividing it by the latent heat of vaporisation of water $\lambda$ to give an equivalent value of $\mathrm{kg} \cdot \mathrm{m}^{-2}$ which is equivalent to $\ell \cdot \mathrm{m}^{-2}$ or $\mathrm{mm}$ depth of water.

\section{Water vapour pressures}

Most available psychrometers do not measure water vapour pressure directly, but give readings of relative humidity based on wet and dry bulb temperatures. For the purpose of calculating the vapour pressure gradient $\delta \mathrm{e} / \delta \mathrm{z}$ the following can be used:

$$
\beta=0.057\left(\mathrm{~T}_{1}-\mathrm{T}_{2}\right) / \mathrm{e}_{\mathrm{sat}}\left(\mathrm{r}_{1}-\mathrm{r}_{2}\right)
$$

where the subscripts 1 and 2 represent the two heights at which

\begin{tabular}{|c|c|}
\hline \multicolumn{2}{|c|}{$\begin{array}{c}\text { TABLE A1 } \\
\text { Saturated water } \\
\text { vapour pressures }\end{array}$} \\
\hline $\begin{array}{c}\text { Temperature } \\
{ }^{\circ} \mathrm{C}\end{array}$ & $\begin{array}{l}\mathbf{e}_{\text {sat }} \\
\mathbf{k P a}\end{array}$ \\
\hline 0 & 0.62 \\
\hline 5 & 0.88 \\
\hline 10 & 1.21 \\
\hline 15 & 1.72 \\
\hline 20 & 2.38 \\
\hline 25 & 3.02 \\
\hline 30 & 4.09 \\
\hline
\end{tabular}
measurements of dry bulb temperature $T$ and relative humidity $r$ are made ( 1 being closer to the ground) and $\mathrm{e}_{\text {sat }}$ is the saturated water vapour pressure at the mean of $\mathrm{T}_{1}$ and $\mathrm{T}_{2}$. Values of $\mathrm{e}_{\text {sat }}$ at various temperatures are given in Table A1 (Lowe 1976).

\section{The Bowen equations}

The Bowen equations are difficult to use in practice because the gradients $\delta \mathrm{T} / \mathrm{dz}$ and $\delta \rho_{\mathrm{v}} / \mathrm{dz}$ are usually small and may be zero or negative. Hence impossible values are frequently obtained for the Bowen ratio $\beta$. In this case it has become customary to set $\beta=0$, making (from Eq. (A5)):

$$
L_{e}=R_{n}-G
$$

and effectively $\mathrm{H}$ is set to zero. Even when possible values are calculated for $\beta$, anomalous values may be found for $\mathrm{H}$. For example, in Fig. 6 anomalously large values for $\mathrm{H}$ were found at about noon. The corresponding depressions in $\mathrm{L}_{\mathrm{e}}$ were caused entirely by the large values for $\mathrm{H}$, which, in turn resulted from inaccuracies in measuring very small temperature and vapour density gradients.

\section{Calculating H}

As an alternative to the Bowen analysis, $\mathrm{H}$ can be calculated by the equation:

$$
\mathrm{H}=\mathrm{z}_{\mathrm{a}}\left(\Delta \overline{\mathrm{T}}_{\mathrm{a}}\right) \mathrm{C}_{\mathrm{a}} \rho_{\mathrm{a}}
$$

in which $\left(\Delta \overline{\mathrm{T}}_{\mathrm{a}}\right)$ is the change in average temperature of the air over height $\mathrm{z}_{\mathrm{a}}$ in time t. $\mathrm{z}_{\mathrm{a}}$ is taken as $2 \mathrm{~m}$, as it seems unlikely that air beyond $2 \mathrm{~m}$ above the soil surface would influence evaporation from the surface.

Eq. (A6) is based on a model proposed by Perrier and Tuzet (1991):

$$
\mathrm{H}=\rho_{\mathrm{a}} \mathrm{C}_{\mathrm{a}}[\mathrm{h}]_{\mathrm{z}_{\mathrm{s}}}^{\mathrm{z}_{\mathrm{R}}} 1_{\mathrm{t}} 1 \int_{0}^{\mathrm{t}}\left[\mathrm{T}\left(\mathrm{z}_{\mathrm{s}}\right)-\mathrm{T}\left(\mathrm{z}_{\mathrm{R}}\right)\right] \mathrm{dt}
$$

in which:

$[\mathrm{h}]_{\mathrm{z}}^{\mathrm{z}_{\mathrm{R}}}$ is a transfer coefficient for heat between the surface level $\left(\mathrm{z}_{\mathrm{S}}\right)$ and a reference level $\left(\mathrm{z}_{\mathrm{R}}\right)$. [T( $\left.\left.\mathrm{z}_{\mathrm{S}}\right)-\mathrm{Tz} \mathrm{z}_{\mathrm{R}}\right]$ is the temperature difference between $z_{S}$ and $z_{R}$.

The density $\left(\rho_{\mathrm{a}}\right)$ and specific heat $\left(\mathrm{C}_{\mathrm{a}}\right)$ of air at atmospheric pressure, at temperatures between 0 and $50^{\circ} \mathrm{C}$ are given in Table A2 (Rogers and Mayhew, 1995).

\begin{tabular}{|c|c|c|}
\hline \multicolumn{3}{|c|}{ TABLE A2 } \\
Density and specific heat of air \\
\hline $\begin{array}{c}\text { Temperature } \\
{ }^{\circ} \mathbf{C}\end{array}$ & $\begin{array}{c}\text { Density } \rho_{\mathrm{a}} \\
\mathbf{k g} \cdot \mathbf{m}^{-3}\end{array}$ & $\begin{array}{c}\text { Specific } \\
\text { heat } \mathbf{C}_{\text {a }} \\
\mathbf{k J}^{\circ} \mathbf{k g}^{-1} \cdot{ }^{\circ} \mathbf{C}^{-1}\end{array}$ \\
\hline 0 & 1.28 & 1.004 \\
25 & 1.18 & 1.005 \\
50 & 1.09 & 1.006 \\
\hline
\end{tabular}

Table A2 shows that the variation of $\mathrm{C}_{\mathrm{a}}$ in the range of temperatures of interest is quite small. As an example of calculating $\mathrm{H}$ :

$$
\text { If } \begin{aligned}
\overline{\mathrm{T}} & =25^{\circ} \mathrm{C} \\
\Delta \overline{\mathrm{T}} & =10^{\circ} \mathrm{C} \text { and } \mathrm{z}_{\mathrm{a}}=2 \mathrm{~m} \\
\mathrm{H} & =2 \times 10 \times 1.005 \times 1.18=24 \mathrm{~kJ} \cdot \mathrm{m}^{-2}
\end{aligned}
$$


Typically, G would have a value of $1000 \mathrm{~kJ} \cdot \mathrm{m}^{-2}$, hence the value of $\mathrm{H}$ is small in comparison with $\mathrm{G}$ and $\mathrm{R}_{\mathrm{n}}$ (in the region of 8 to 10 $\mathrm{MJ} \cdot \mathrm{m}^{-2}$ ), and $\mathrm{H}$ and can usually be set to zero with little error.

Alternatively, an "aerodynamic" equation (e.g. Tyson and Preston-Whyte, 2000) can be used to calculate H. One form of an aerodynamic equation is:

$$
\mathrm{H}=\rho_{\mathrm{a}} \mathrm{C}_{\mathrm{a}} \mathrm{k}^{2} \frac{\left(\mathrm{u}_{2}-\mathrm{u}_{1}\right)\left(\mathrm{T}_{2}-\mathrm{T}_{1}\right)}{\left.\left(\ln _{\mathrm{z}}\right)^{\frac{z_{2}}{2}}\right)^{2}}
$$

where:

$\mathrm{C}_{\mathrm{a}}=$ specific heat for air $\left(1.005 \mathrm{~kJ} \cdot \mathrm{kg}^{-1} \cdot{ }^{\circ} \mathrm{C}^{-1}\right)$

$\mathrm{k}=$ Von Karman's constant $=0.4$.

$\mathrm{u}_{1}$ and $\mathrm{u}_{2}$ are wind velocities at heights $\mathrm{z}_{1}$ and $\mathrm{z}_{2}$

$\mathrm{T}_{1}$ and $\mathrm{T}_{2}$ are temperatures at heights $\mathrm{z}_{1}$ and $\mathrm{z}_{2}$. As an example, take

$$
\begin{aligned}
& \mathrm{u}_{1}=2 \mathrm{~m} \cdot \mathrm{s}^{-1}, \mathrm{u}_{2}=2.5 \mathrm{~m} \cdot \mathrm{s}^{-1} \\
& \mathrm{z}_{1}=0.2 \mathrm{~m}, \mathrm{z}_{2}=2.0 \mathrm{~m} . \text { Then with } \\
& \rho_{\mathrm{a}}=1.2 \mathrm{~kg} \cdot \mathrm{m}^{-3} \\
& \mathrm{~T}_{1}=20^{\circ} \mathrm{C}, \mathrm{T}_{2}=21^{\circ} \mathrm{C} \\
& \mathrm{H}=0.018 \mathrm{~kW} \cdot \mathrm{m}^{-2}
\end{aligned}
$$

Over 12 hours of sunshine this would accumulate to

$$
\Sigma \mathrm{H}=788 \mathrm{~kJ} \cdot \mathrm{m}^{-2}
$$

Hence by this method, $\mathrm{H}$ has about the same value as G. Note, however, that if there is no wind, or no wind gradient, $\mathrm{H}$ will be zero by this method. Also if the temperature gradient is zero or reversed, $\mathrm{H}$ will come out as zero or negative, even if the average air temperature has increased. Hence the basis for equation (A6b) and other similar equations appears doubtful and equation (A6) is preferred.

\section{Calculating G}

$\mathrm{G}$ is calculated from the depth of soil heated diurnally by the incoming net radiation, i.e.

$$
\mathrm{G}=\mathrm{z}_{\mathrm{G}}(\Delta \overline{\mathrm{T}}) \mathrm{C}_{\mathrm{G}} \rho_{\mathrm{G}}
$$

in which:

$$
\begin{aligned}
& \mathrm{z}_{\mathrm{G}}=\text { depth of soil heated }(\mathrm{m})\left(\mathrm{z}_{\mathrm{G}} \text { is usually } 0.2 \text { to } 0.25 \mathrm{~m}\right) \\
& (\Delta \overline{\mathrm{T}}) \quad=\quad \text { the average measured rise in temperature over } \\
& \text { depth } z_{G} \\
& \mathrm{C}_{\mathrm{G}}=\text { the specific heat of the soil }\left(\mathrm{kJ} \cdot \mathrm{kg}^{-1} \cdot{ }^{\circ} \mathrm{C}^{-1}\right) \\
& \rho_{\mathrm{G}} \quad=\text { bulk density of the soil }\left(\mathrm{kg} \cdot \mathrm{m}^{-3}\right)
\end{aligned}
$$

The specific heat of soil is conventionally taken as (Campbell Scientific, 1987):

$$
\mathrm{C}_{\mathrm{G}}=\mathrm{C}_{\mathrm{Gd}}+\mathrm{wC}_{\mathrm{w}}
$$

in which

$$
\begin{aligned}
& \begin{array}{l}
\mathrm{C}_{\mathrm{Gd}}=\text { specific heat of the dry soil particles; } \\
\begin{array}{ll}
\mathrm{C}_{\mathrm{w}}= & \text { specific heat of water; and } \\
\mathrm{W} & =\text { gravimetric water content of the soil (mass of } \\
& \text { water/mass of solids). }
\end{array} \\
\mathrm{C}_{\mathrm{Gd}} \text { has a value of about } 0.85 \mathrm{~kJ} \cdot \mathrm{kg}^{-1} \cdot{ }^{\circ} \mathrm{C}^{-1} \\
\mathrm{C}_{\mathrm{w}} \text { has a value of } 4.19 \mathrm{~kJ} \cdot \mathrm{kg}^{-1} \cdot{ }^{\circ} \mathrm{C}^{-1}
\end{array}
\end{aligned}
$$

Because $\mathrm{C}_{\mathrm{w}}$ is so much larger than $\mathrm{C}_{\mathrm{Gd}}$, the water content of the soil is very important and should be measured. It may also be necessary to allow for variations in water content during the course of a set of measurements. As an example, for a soil having a dry density of $1390 \mathrm{~kg} \cdot \mathrm{m}^{-3}, \mathrm{C}_{\mathrm{G}}$ varies from $2.11 \mathrm{~kJ} \cdot \mathrm{kg}^{-1} \cdot{ }^{\circ} \mathrm{C}^{-1}$ for a water content of $30 \%$ to $1.69 \mathrm{~kJ} \cdot \mathrm{kg}^{-}{ }^{\circ} \mathrm{C}^{-1}$ for a water content of $20 \%$. If the depth of soil affected by diurnal heating is $150 \mathrm{~mm}, \mathrm{G}$ will vary from 572 $\mathrm{kJ} .{ }^{\circ} \mathrm{C}^{-1}$ at a water content of $30 \%$ to $422 \mathrm{~kJ} .{ }^{\circ} \mathrm{C}^{-1}$ at a water content of $20 \%$, a difference of $35 \%$ in values.

Note also that in the above examples for $\mathrm{G}$ and $\mathrm{H}$ (equations (A6) and (A7]), for the same change in temperature:

$\mathrm{G} / \mathrm{H}=252$, i.e. $\mathrm{H}$ represents only $0.4 \%$ of $\mathrm{G}$. Even if $\mathrm{z}_{\mathrm{a}}$ (the height of air involved) were doubled to $4 \mathrm{~m}$, H would still constitute a small proportion of G.

\section{Experimental confirmation of addition rule for CG}

An experimental check has been made on both the numerical values usually used for $\mathrm{C}_{\mathrm{Gd}}$ and the addition rule (Eq. (A8)) for calculating $\mathrm{C}_{\mathrm{G}}$ for moist soils. The check took the form of a simulated set of field measurements in which a shallow circular pan made of fibrereinforced cement, and measuring $500 \mathrm{~mm}$ in diameter and $120 \mathrm{~mm}$ deep was filled with a $110 \mathrm{~mm}$ deep layer of dry crushed quartzite ranging in particle size from $19 \mathrm{~mm}$ down to sand sizes. The pan was contained in a larger box, supported on a $150 \mathrm{~mm}$ layer of polystyrene beads and surrounded on its sides by the same insulation with a minimum width of $150 \mathrm{~mm}$. Thermocouples were buried in the gravelly sand at depths of 5,50 and $110 \mathrm{~mm}$, on the axis of the pan.

The specimen was then exposed to the sun at sunrise and a series of measurements were made through the day of net incoming radiation and soil temperature. The following day the soil was saturated by pouring water over it until the water level was close to the surface, but without any free water being exposed, and the measurements were repeated. The test specimen was then allowed to dry in the sun for several days until the water content was approximately halved (13.0\% to $6.8 \%$ ) and the measurements were repeated. After a further period of drying, the final set of measurements was made at a water content of $2.7 \%$.

The results of the measurements are shown in Fig. A1. Figure A1a represents the observed relationships between cumulative net radiation $\left(\Sigma \mathrm{R}_{\mathrm{n}}\right)$ and the mean increase in temperature of the sand $(\Sigma \Delta \overline{\mathrm{T}})$. Figure A1b shows three temperature profiles measured at the maximum value of $\Sigma \Delta \overline{\mathrm{T}}$. The inclined dashed lines in Fig. A1a represent theoretical relationships between $\Sigma \mathrm{R}_{\mathrm{n}}$ and $\Sigma \Delta \overline{\mathrm{T}}$ if there were no heat losses by re-radiation into the air, or conversion of $\Sigma R_{n}$ into latent heat of evaporation $\left(\mathrm{L}_{\mathrm{e}}\right)$. The values for $\mathrm{C}_{\mathrm{G}}$ were calculated from Eq. (A8) for the measured dry density of the sand of $1840 \mathrm{~kg} \cdot \mathrm{m}^{-3}$. For the early part of each heating curve, when losses were probably small, the theoretical curves agree quite well with the measurements, which show approximately the theoretical trend of Eq. (A8) as the water content was varied from 0 to $13 \%$. Hence the basis for using Eq. (A8) appears to be satisfactory, although, because of diurnal changes of water content, the value of $\mathrm{G}$ cannot be calculated with certainty.

Figure A1c shows a similar experiment using the same pan, filled with $135 \mathrm{~mm}$ of water. In this case, agreement between the theoretical value of $\mathrm{C}_{\mathrm{w}}$ and the observed heating curve for the water was not nearly as good, indicating a greater rate of heat loss from the water (probably arising from convection currents) than from the sand specimens. 


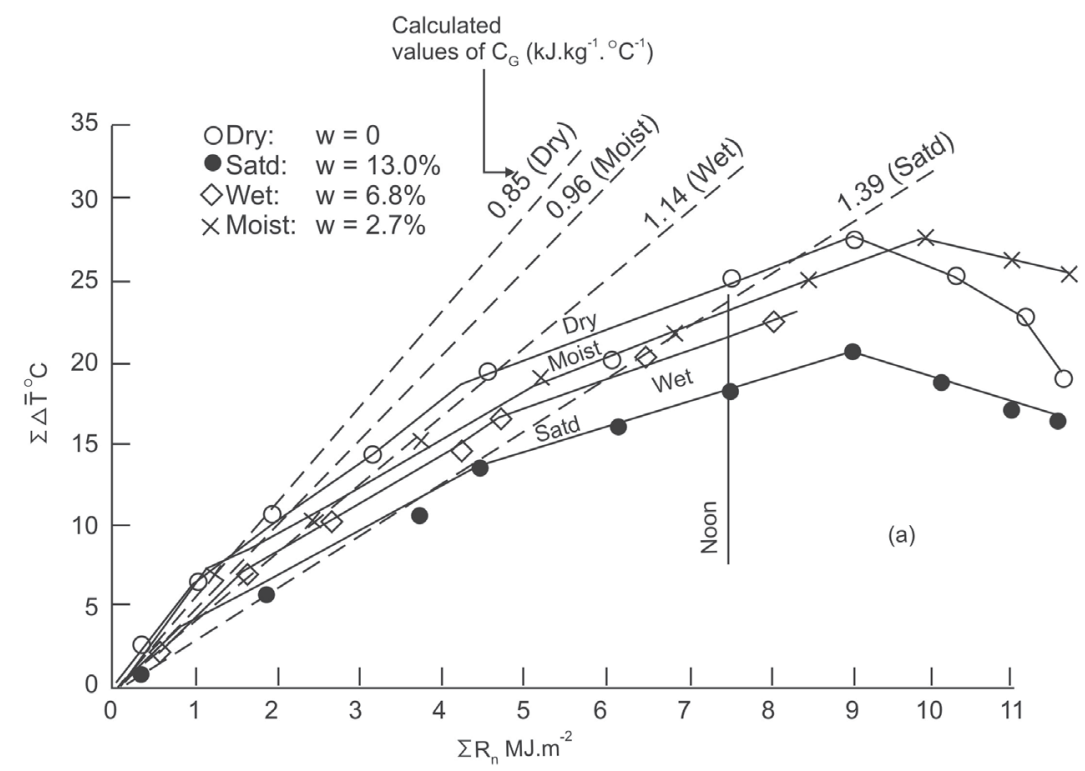

Figure A1

Experimental check on calculation of $C_{G}$ for soil over a range of water contents $(w)$
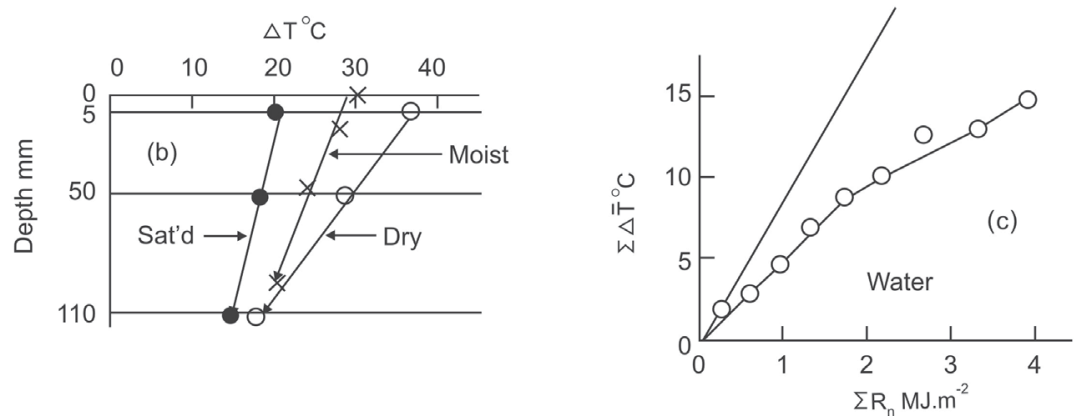

\section{A note on wind energy We}

Suppose that a layer of air with density $\rho_{\mathrm{a}}$ moves across the ground surface at velocity $\mathrm{u}$. Consider a portion of the layer $\mathrm{z}$ in height moving across an area of surface measuring $1 \mathrm{mx} 1 \mathrm{~m}$. The energy of this volume of air will be:

$1 / 2 \rho_{\mathrm{a}} \mathrm{zu}^{2}$

(The units will be $\mathrm{kg} \cdot \mathrm{m} \cdot \mathrm{s}^{-2} \cdot \mathrm{m}=\mathrm{Nm}=\mathrm{J}$ )

The time taken for the air to pass over the $1 \mathrm{~m}^{2}$ area will be $1 / \mathrm{u}$. If a fraction $\mathrm{x}$ of the air's energy is extracted by shearing across the surface, the energy will be extracted at a rate of:

$\mathrm{x} / 2 . \rho_{\mathrm{a}} \mathrm{zu}^{3}=\mathrm{W}_{\mathrm{E}}$

(Units will be $\mathrm{J} \cdot \mathrm{s}^{-1}$ ).
As an example, if $\mathrm{z}=2 \mathrm{~m}, \rho=1.2 \mathrm{~kg} \cdot \mathrm{m}^{-3}$ and $\mathrm{u}=5 \mathrm{~m} \cdot \mathrm{s}^{-1}$,

$$
\mathrm{W}_{\mathrm{E}}=150 \mathrm{xW}
$$

If $\mathrm{x}=1 \%$ (which seems a reasonable proportion) $\mathrm{W}_{\mathrm{E}}=1.5 \mathrm{~W} \cdot \mathrm{m}^{-2}$. Over a day of $24 \mathrm{~h}$, energy extracted would be:

$$
\mathrm{W}_{\mathrm{E}}=129.6 \mathrm{~kJ} \cdot \mathrm{m}^{-2}
$$

On a sunny day $\mathrm{R}_{\mathrm{n}}$ would typically amount to $6000 \mathrm{~kJ} \cdot \mathrm{m}^{2}$ (see Figs. 8, 9 or 10).

Hence on this basis, wind energy at moderate wind velocities would be a small component of the surface energy balance. 